\title{
Tumor Angiogenesis as a Target for Dietary Cancer Prevention
}

\author{
William W. Li, Vincent W. Li, Michelle Hutnik, and Albert S. Chiou
}

The Angiogenesis Foundation, One Broadway, 14th Floor, Cambridge, MA 02142, USA

Correspondence should be addressed to William W. Li, wli@angio.org

Received 17 June 2011; Accepted 4 July 2011

Academic Editor: Kalpna Gupta

Copyright ( 2012 William W. Li et al. This is an open access article distributed under the Creative Commons Attribution License, which permits unrestricted use, distribution, and reproduction in any medium, provided the original work is properly cited.

\begin{abstract}
Between 2000 and 2050, the number of new cancer patients diagnosed annually is expected to double, with an accompanying increase in treatment costs of more than $\$ 80$ billion over just the next decade. Efficacious strategies for cancer prevention will therefore be vital for improving patients' quality of life and reducing healthcare costs. Judah Folkman first proposed antiangiogenesis as a strategy for preventing dormant microtumors from progressing to invasive cancer. Although antiangiogenic drugs are now available for many advanced malignancies (colorectal, lung, breast, kidney, liver, brain, thyroid, neuroendocrine, multiple myeloma, myelodysplastic syndrome), cost and toxicity considerations preclude their broad use for cancer prevention. Potent antiangiogenic molecules have now been identified in dietary sources, suggesting that a rationally designed antiangiogenic diet could provide a safe, widely available, and novel strategy for preventing cancer. This paper presents the scientific, epidemiologic, and clinical evidence supporting the role of an antiangiogenic diet for cancer prevention.
\end{abstract}

\section{Introduction}

Cancer now affects as many as 24 million people worldwide, and results in over six million deaths each year [1]. In the United States, men and women have a $43 \%$ and $38 \%$ chance, respectively, of being diagnosed with any type of cancer during their lifetime [2]. Despite advances in the early detection of cancer, most malignancies are still diagnosed and treated at advanced stages, with a limited range of therapeutic options and poor overall survival. Simultaneously, cancer treatment costs are escalating, from $\$ 125$ billion annually in the US in 2010 to a projected $\$ 207$ billion by 2020 [3]. Cancer prevention is, thus, a key opportunity for managing the cancer pandemic. Unlike interventional approaches delivered to patients diagnosed with advanced cancer, preventative strategies must be suitable for healthy individuals and have low systemic toxicity, inhibiting microscopic tumor growth with minimal adverse effects on healthy tissues [4].

It is now well established that solid tumor growth is dependent upon angiogenesis, the growth of new blood vessels [5-10]. During early stages of tumorigenesis, the induction of angiogenesis by cancer cells is a critical event separating the preinvasive and dormant form of cancer from the invasive and metastatic phases of malignant growth. Multiple studies have demonstrated that the degree of tumor vascularity correlates positively with disease stage, the likelihood of metastases, and cancer recurrence $[11,12]$. Angiogenesis also plays a role in hematogenous malignancies, such as leukemia, lymphoma, and multiple myeloma, as well as in premalignant myelodysplastic syndromes [1317]. In these pathologies, vascular endothelial cells sustain and promote malignant cell growth by secreting paracrine survival factors $[18,19]$.

Antiangiogenic therapy has been validated as an effective cancer treatment strategy for a growing number of cancer types, including colorectal, renal, liver, lung, brain, pancreatic neuroendocrine tumors (NET), gastrointestinal stromal tumors (GIST), multiple myeloma, and myelodysplastic syndrome [20]. More than 120 novel antiangiogenic agents are in clinical, trials [20-22]. Importantly, a growing body of preclinical, clinical and epidemiological data is demonstrating that angiogenesis inhibition can be applied for achieving cancer prevention $[23,24]$. This paper presents the scientific and clinical evidence supporting antiangiogenesis as a rational strategy for the prevention of cancer, exploiting factors that are naturally present in dietary sources.

\section{The Physiological State of Angiogenesis Regulation}

The human body contains 60,000 miles of blood vessels, including 19 billion capillaries. All normal cells in the body 
are located no further than $100-200 \mu \mathrm{m}$ from the nearest capillary, the diffusion limit of oxygen [25]. Capillaries not only deliver oxygen and micronutrients to tissues, but the endothelial cells comprising them secrete paracrine growth and survival signals that influence adjacent nonvascular cells [18]. Under physiological conditions, the rate of cell proliferation is balanced with the rate of cell death (apoptosis), so there is no net tissue growth. Expansion of tissue mass requires angiogenesis to support increased metabolic demand [9]. In normal healthy adults, angiogenesis is constitutively suppressed except for brief bursts during the female reproductive cycle (endometrial regeneration, corpus luteum formation), pregnancy (placentation), and wound healing (granulation) [26-30]. The physiological state is thus maintained in a constitutive state of suppressed angiogenesis by endogenous inhibitory mechanisms opposing the action of angiogenic growth and other stimulating factors.

2.1. Angiogenic Growth Factors. More than 30 endogenous molecules have been identified as angiogenic factors (Table 1). These share the ability to stimulate neovascularization in vivo and induce endothelial proliferation, migration, or capillary tube formation in vitro. Basic fibroblast growth factor (bFGF or FGF2) was the first angiogenic factor to be identified from a tumor extract, but vascular endothelial growth factor/vascular permeability factor (VEGF/VPF) is the best studied [30]. VEGF is a potent endothelial mitogen that increases vascular permeability, and also induces Bcl2, promoting vascular survival [31-34]. VEGF is expressed by all human tumors studied and its receptors (VEGFR-1, -R2, -R3 and -R4) are expressed selectively on angiogenic endothelial cells [35]. Placental growth factor (PlGF) plays a specific role in pathological neovascularization by recruiting bone marrow-derived vascular stem cells to disease sites $[36,37]$. Other factors include platelet-derived growth factor (PDGF), platelet-derived endothelial cell growth factor (PD-ECGF), interleukin-3 (IL-3), interleukin-8 (IL-8), transforming growth factor- $\beta$ (TGF $\beta)$, and tumor necrosis factor-alpha (TNF $\alpha)[38,39]$. Other angiogenic factors are neuregulin, a ligand for the ErbB receptor, and keratinocyte growth factor (KGF or FGF-7) [40, 41]. Angiogenic factors are observed at low levels or undetectable in the circulation in normal, healthy subjects. By contrast, markedly elevated levels of factors such as bFGF, VEGF, and PD-ECGF are present in the serum, urine, and cerebrospinal fluid of cancer patients $[42,43]$.

2.2. Physiological Inhibition of Angiogenesis. Angiogenesis inhibitory activity was first discovered in studies of cartilage, a naturally avascular tissue [44]. Numerous endogenous antiangiogenic molecules have subsequently been identified, including troponin-1, tissue inhibitors of matrix metalloproteinases (TIMPs), chondromodulin I, connective tissue-growth factor (CTGF), decorin, metastatin, pigment epithelium-derived factor (PEDF) thrombospondin-1 and -2 , interferons, tetrahydrocortisol-S, platelet factor-4, and protamine [45-60]. Other inhibitors, such as canstatin, tumstatin, and arresten, are present in the basement membrane surrounding established blood vessels [61-63].
TABle 1: Angiogenic factors.

Angiogenin
Angiopoietin-1
Adrenomedullin
Del-1
Fibroblast growth factor-1 (acidic FGF, FGF1)
Fibroblast growth factor-2 (basic FGF, FGF2)
Follistatin
Granulocyte-colony-stimulating factor (G-CSF)
Hepatocyte growth factor/scatter factor (HGF/SF)
Interleukin-3 (IL-3)
Interleukin-8 (IL-8)
Intermedin
Keratinocyte growth factor (FGF-7)
Leptin
Midkine
Neuregulin
Osteogenic protein-1
Placental growth factor (PlGF)
Platelet-derived endothelial-cell growth factor (PD-ECGF)
Platelet-derived growth factor (PDGF)
Pleiotrophin
Progranulin
Proliferin
Transforming growth factor- $\alpha$ (TGF $\alpha$ )
Transforming growth factor- $\beta$ (TGF $\beta$ )
Tumor necrosis factor- $\alpha$ (TNF $\alpha$ )
Vascular endothelial growth factor/vascular permeability
factor (VEGF/VPF)
Pot

A separate and distinct class of inhibitors is comprised of proteolytic fragments derived from cleaved larger molecules. Angiostatin is an internal fragment of plasminogen and specifically inhibits endothelial cell proliferation [64]. Enzymes such as macrophage-derived elastase and serine proteases generate angiostatin or angiostatinlike fragments $[65,66]$. Endostatin, a $20-\mathrm{kDa}$ fragment of collagen XVIII, is a specific angiogenesis inhibitor that induces endothelial apoptosis $[67,68]$. Both angiostatin and endostatin were discovered in the serum of tumorbearing experimental mice, suggesting that tumor-associated protease activity generates these inhibitors. Removal of the primary tumor led to a marked decline in serum angiostatin and endostatin, followed by rapid angiogenic growth of metastatic lesions $[9,69]$. Endostatin is present at a low circulating level in normal subjects [70]. Collectively, these endogenous angiogenesis inhibitors play a dominant role in suppressing angiogenesis in health and contribute to tumor dormancy (Table 2).

2.3. Balance and Imbalance of Angiogenesis. Vascular growth is physiologically governed by a homeostatic balance between 
TABLE 2: Endogenous inhibitors of angiogenesis.

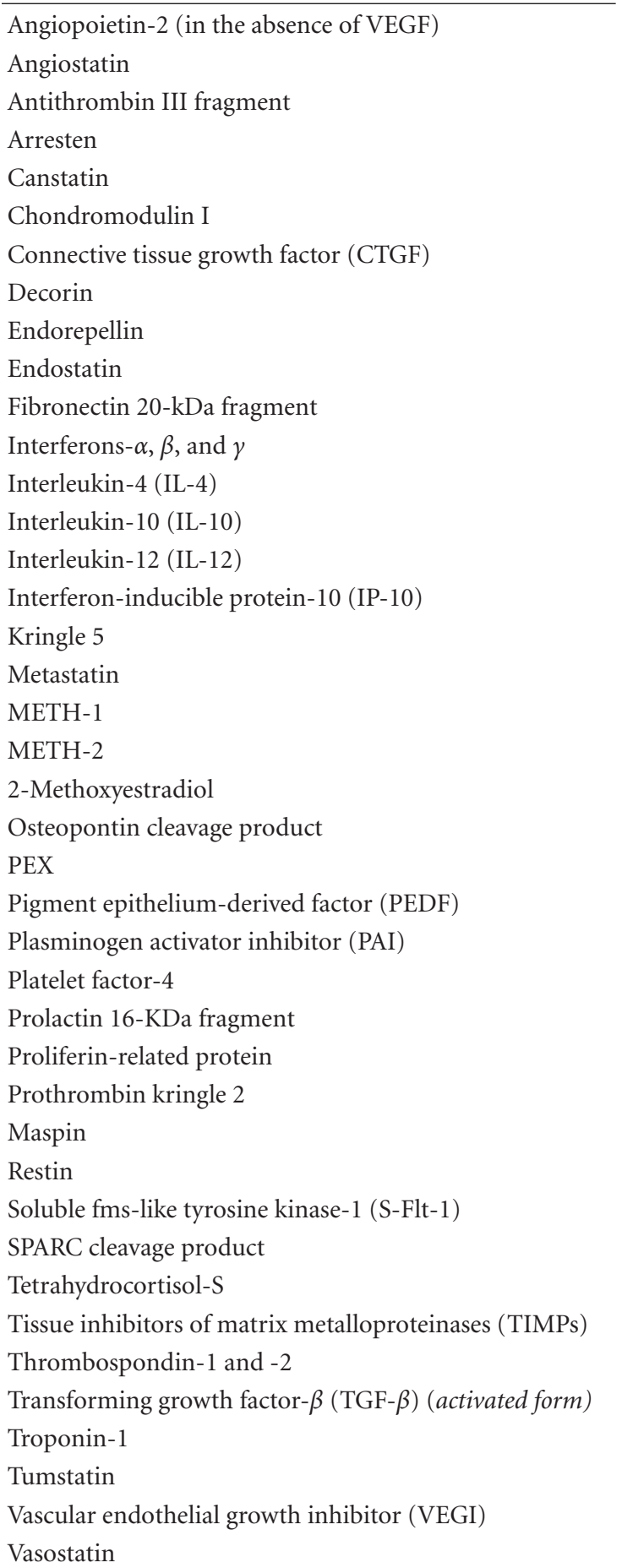

positive and negative angiogenesis regulators, so that neovascularization is normally suppressed [71]. Vascular proliferation occurs when angiogenic growth factor production is upregulated, or when expression of endogenous inhibitors is downregulated, or when both events occur simultaneously [72-74]. The genetic regulators of angiogenesis are closely related to tumor growth promotion and suppression (Table 3). Gene knockout studies in mice have shown that
TABLe 3: Genetic control of angiogenesis.

\begin{tabular}{l}
\hline Id 1 p53 \\
Id3 Rb \\
HIF-1a VHL \\
K-ras PTEN \\
N-myc trk B \\
c-myc p16INK4a \\
c-fos \\
c-src \\
c-myb \\
c-jun \\
HER2/neu \\
EGFT \\
Raf \\
Mek \\
p73 \\
Del-1 \\
FzD \\
Bcl2 \\
MDNM2 \\
PML-RAR \\
ElF-4E
\end{tabular}

Id 1 and Id3, peptides that control cell differentiation by interfering with DNA binding of transcription factors, are required for normal vascular formation and induction of angiogenesis in tumor-bearing animals [75]. The activated forms of the oncogenes H-ras, v-raf, c-myc, c-src, Her-2/neu, and p73 are associated with cellular production of VEGF as well as tumorigenesis [76-83]. Several tumor-suppressor genes regulate angiogenesis inhibition, including p53, Rb, $\mathrm{vHL}$, phosphatase and tensin homolog (PTEN), and trk B [84] Wild-type p53 controls expression of the angiogenesis inhibitor thrombospondin and decreases tumor neovascularization; mutant p53 leads to the opposite effect [73]. The retinoblastoma $(\mathrm{Rb})$ gene and the von Hippel-Lindau (vHL) gene both downregulate VEGF expression; their mutation leads to VEGF production, angiogenesis, and tumor growth $[85,86]$.

2.4. The Avascular Dormant Phase of Cancer. Microscopic cancer cells are commonly present in the healthy adult, the result of errors during replication of 60-90 trillion cells. To acquire sustenance, the incipient tumors (60-80 cells) may migrate toward existing host vessels, a process known as vessel cooption, but their growth remains limited [87-89]. Tumors are capable of growth to approx $0.5 \mathrm{~mm}^{3}$ in diameter $(10,000,000$ cells) before reaching a steady state of growth. Beyond this size, their metabolic demands exceed the supply of oxygen and nutrients obtained by passive diffusion from nearby blood vessels. This state corresponds to carcinoma in situ, and the rate of tumor cell proliferation is balanced by apoptosis [90]. Such microscopic tumors may exist for years without clinical detection. 

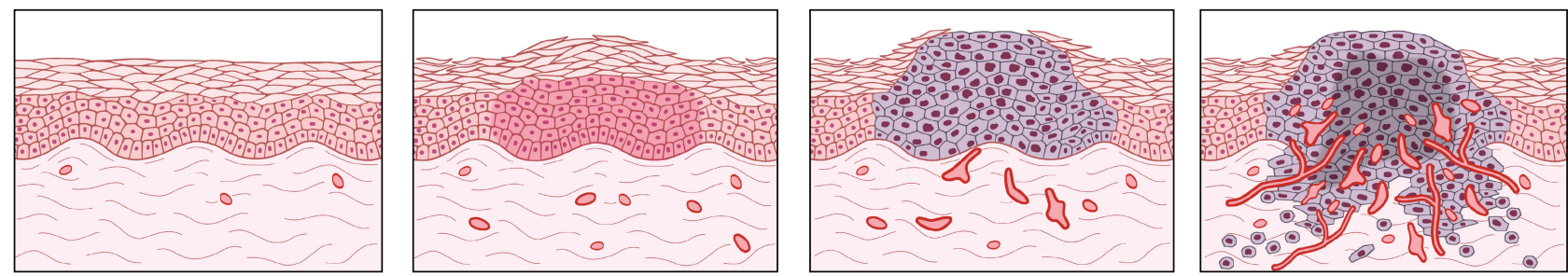

Figure 1: The switch to the angiogenic phenotype occurs during multistage tumorigenesis. As malignancy develops, cells progress from a prevascular stage (normal to early hyperplasia) to a vascular stage (late hyperplasia to dysplasia to invasive carcinoma). Angiogenesis becomes clearly evident during dysplasia and is critical for further growth. Targeting tumor angiogenesis may be a novel strategy for preventing cancer. (Reprinted by permission from the Angiogenesis Foundation. Copyright 2011 by The Angiogenesis Foundation. All rights reserved).

Autopsy studies have shown that these microscopic cancers are present in the breasts of up to $40 \%$ of women between the ages of 40 and 50 years, and in $50 \%$ of prostates in men between 50 and 60 years. By age 70, microscopic cancers are detected in the thyroids of virtually everyone. Most of these tumors never become clinically significant, leading to the concept of "cancer without disease" as a normal state during aging. Physiological angiogenesis inhibition is regarded as one of the mechanisms that prevent microscopic cancers from converting to a malignant phenotype.

\subsection{The "Switch" to the Angiogenic Phenotype during Mul-} tistep Tumorigenesis. To expand beyond the limits of the preexisting vascular supply, tumors recruit new blood vessels from surrounding vessels, an event known as the "switch" to the angiogenic phenotype [91] (see Figure 1). Three classic studies employing transgenic mice have delineated this switch as normal cells undergo the transition from normalcy to hyperplasia to dysplasia, and finally to frank carcinoma.

In a model of spontaneous $\beta$-islet cell tumor formation, Rip1-Tag2 transgenic mice selectively express the SV40 Tantigen oncogene in their insulin producing $\beta$ cells and undergo a predictable sequence of multistep tumorigenesis $[71,92,93]$. The transformed $\beta$-cells are localized to approx 400 islets in the pancreas, of which $100 \%$ express the oncogene. Over time, $50-70 \%$ of these islets become hyperplastic nodules. A distinct angiogenic stage occurs at 6-7 wk of age between the hyperplastic stage and the time at which subset islets become invasive carcinomas at 12-16 weeks. The angiogenic capacity of these lesions is observed as visible intense tumor vascularization, accompanied by induction of capillary sprouting, endothelial proliferation, and a starburst-like convergence of capillaries when islets are harvested in vivo and cocultured with endothelial cells in vitro. Importantly, nonangiogenic islets are unable to grow beyond $0.6-0.8 \mathrm{~mm}^{3}$ in size, whereas the small subset of angiogenic islets can expand into a lethal tumor burden [94].

A second study utilized the bovine papillomavirus oncogene in a transgenic mouse model of dermal fibrosarcoma $[95,96]$. Distinct stages of tumorigenesis are observed, from normal cells to a proliferative hyperplastic stage (mild and aggressive fibromas) to neoplasia (fibrosarcoma). The preneoplastic fibromas grow horizontally within the dermis as thin avascular lesions, and the fibrosarcomas are expansile and densely vascularized. Angiogenesis is first observed during the late preneoplastic stage (aggressive fibroma) and sustained until death of the animals by fibrosarcoma. Aggressive fibromas and fibrosarcomas secrete bFGF. By contrast, bFGF is not secreted by normal cells or by mild fibromas.

A third study involved K14-HPV16 transgenic mice in which the human papillomavirus (HPV) type 16 oncogene is targeted to expression in basal cells of the epidermis by regulatory elements of the human keratin-14 promoter [97]. These basal keratinocytes undergo sequential changes from normal cells (no vascularization) to hyperplasia (mild vascularization from the underlying dermis) to dysplasia (abundant vessels under the basement membrane in close apposition to aberrant keratinocytes) to squamous cell carcinoma (intense angiogenesis breaching the basement membrane into the tumor). In hyperplasia, dysplasia, and at the invading cancer front, angiogenesis is associated with mast cell infiltration and degranulation [98]. Mast cells contain numerous angiogenic stimulators in their secretory granules, such as the serine protease MCP-4, VEGF, bFGF, $\operatorname{TGF} \beta, \mathrm{TNF} \alpha$, and IL-8 $[99,100]$. In dysplasia and carcinoma, tissue expression of VEGF was increased, correlating to increased tumor vessel density [101].

Together, these data demonstrate that angiogenesis is a discrete, genetically regulated and rate-limiting step during multistep tumorigenesis, that the transition from prevascular to vascular phase is accompanied by the production and release of one or more angiogenic growth factors, and that host inflammatory cells may amplify the angiogenic switch by contributing additional stimuli.

2.6. The Vascular Phase of Cancer. The onset of angiogenesis precedes an exponential phase of tumor growth accompanied by local organ invasion. The velocity of angiogenic capillary growth ranges from 0.223 to $0.8 \mathrm{~mm} /$ day [102104]. Studies of avascular tumor explants placed in the anterior chamber of the eye show that once new vessels reach the explant, tumors can expand 16,000-fold in size in $2 \mathrm{wk}$ [105]. During this expansion, cancer cells grow as a cuff around each new microvessel with a thickness of 50-200 $\mu \mathrm{m}$. In this configuration, one endothelial cell supports the metabolic needs of 5-100 cancer cells [106, 107]. Eventually, invading blood vessels occupy $1.5 \%$ of the tumor volume [108]. Tumor angiogenesis also facilitates cancer metastases 
TABLE 4: Approved antiangiogenic agents and cancer indications.

\begin{tabular}{ll}
\hline Bevacizumab (Genentech/Roche) & Colon, Lung, Breast, Brain, Kidney \\
Cetuximab (Bristol-Myers Squibb/Imclone) & Colon, Head and Neck \\
Endostatin (Simcere) ${ }^{\dagger}$ & Lung \\
Erlotinib (Genentech/Roche/OSI) & Lung, Pancreatic \\
Everolimus (Novartis) & Kidney, Pancreatic/NET*, Brain/SEGA** \\
Imiquimod (Graceway/3M) & Actinic keratosis, Basal cell carcinoma \\
Interferon alfa (Roche/Schering) & Melanoma, Kaposi's sarcoma \\
Lenalidomide (Celgene) & Myleodysplastic syndrome, Multiple myeloma \\
Pazopanib (GlaxoSmithKline) & Kidney \\
Sorafenib (Bayer/Onyx) & Kidney, Liver \\
Sunitinib (Pfizer) & Kidney, GIST, Pancreatic/NET* \\
Temsirolimus (Wyeth) & Kidney, Lymphoma \\
Thalidomide (Celgene) & Multiple myeloma \\
Vandetanib (AstraZeneca) & Thyroid \\
${ }^{\dagger}$ Available only in China. & \\
$*^{*}$ Neuroendocrine tumor. & \\
$*^{*}$ Subependymal giant cell astrocytoma, associated with tuberous sclerosis. & \\
Source: Angiotracker, The Angiogenesis Foundation (http://www.angio.org/). &
\end{tabular}

by allowing cells to exit through the neovascular network into the systemic circulation [109]. Elegant studies of mammary carcinomas in mice have shown that a $1 \mathrm{~cm}$ tumor sheds up to $4 \times 10-6$ malignant cells into the circulation every $24 \mathrm{~h}$ [110].

\section{Targeting Tumor Angiogenesis for Cancer Prevention}

The concept of "antiangiogenesis" was first proposed in 1971 by Judah Folkman, who hypothesized that inhibition of neovascularization at an early stage of cancer development could prevent tumor growth and metastases and maintain tumor dormancy [7]. A vast literature establishes that angiogenesis inhibition is an effective strategy to restrict cancer growth in animal models bearing a wide variety of cancers $[8,111]$. To date, more than 300 angiogenesisinhibitory molecules have been identified as potential drug candidates, including many natural and synthetic chemical entities (reviewed in 55). Selective targeting of angiogenic blood vessels is possible as a result of differential proliferation rates between normal and tumor-associated endothelium. The normal vasculature is highly quiescent, with only one in every 10,000 endothelial cells dividing at any given time, and a physiological doubling time ranging from 47 to 20,000 days [112-114]. In contrast, the doubling rate for tumor endothelium is $2-13$ days. Thus, antiangiogenic agents are selective in inhibiting proliferating tumor vasculature, but do not affect normal blood vessels.

3.1. Targets of Tumor Angiogenesis. Specific molecular and cellular targets have been identified for tumor angiogenesis. These include targets present during the orderly events characterizing new blood vessel growth [115]. These include (1) angiogenic growth factor production, release, and receptor activation, (2) degradation of vascular basement membrane,
(3) endothelial proliferation, migration, and survival, (4) blood vessel sprouting and invasion, (5) tubular morphogenesis, (6) arterial-venous patterning, (7) vascular maturation, and (8) recruitment of endothelial stem cells.

3.2. Clinical Principles of Antiangiogenic Therapy. The clinical development of antiangiogenic therapy began in the late 1980s. The first successful treatment of a vascular tumor (pulmonary hemangiomatosis) occurred in 1989 using interferon- $\alpha 2 \mathrm{a}$ as an antiendothelial agent [116]. The first drug to enter formal clinical trials as an angiogenesis inhibitor was TNP-470 in 1992 [117]. Since 2004, more than 14 different antiangiogenic agents have been demonstrated to be efficacious in treating solid and hematogenous cancers, primarily in the setting of advanced disease (see Table 4). To date, most agents that are specific or selective for angiogenesis are well tolerated in humans, with fewer serious (Grade 3 and 4) toxicities observed in their clinical trials when compared to cytotoxic chemotherapy drugs [118120]. Because only proliferating endothelium is targeted, the traditional side effects of chemotherapy, such as leukopenia, alopecia, and mucositis, are rarely observed. With some antiangiogenic agents, a maximum tolerated dose (MTD) cannot be determined [70]. This has led some clinical investigations to incorporate pharmacodynamic techniques for determining the optimal biological dose (OBD) of agents in clinical trials.

Collectively, translational research studies have shown that overall disease burden is important to consider in the evaluation of the clinical effects of any antiangiogenic agent. Advanced cancers contain well-established, extensive vascular networks that may respond minimally to angiogenesis inhibitors. Vascular destructive agents, also known as vascular targeting agents, may be required to achieve a clinically significant effect on tumor perfusion [121-123]. Indeed, most preclinical studies of angiogenesis inhibitors 
demonstrate drug efficacy in the setting of incipient disease (prevention) or small tumors (early intervention). Clinical trials of the same agents, however, have often enrolled patients with advanced, metastastic, and heavily pretreated disease, perhaps explaining differences between mice studies and the results of human trials [124]. Antiangiogenic therapy in the adjuvant setting to suppress minimal residual disease, or as an intervention for early-stage disease or cancer prevention, has been proposed as the scenario of the greatest clinical benefit using angiogenesis inhibitors [125].

The remainder of this paper is devoted to discussing the potential for angiogenesis inhibitors for prevention of cancer.

\section{Early Intervention and Cancer Prevention}

4.1. Early Intervention. Angiogenesis inhibition offers an opportunity to interrupt an early, rate-limiting step in tumorigenesis $[126,127]$. Suppression of pathological bloodvessel growth prevents early tumors from progressing to the malignant phenotype. Clinical correlates to preinvasive angiogenic lesions are commonly encountered in breast (ductal carcinoma in situ-DCIS), cervix (cervical intraepithelial neoplasia-CIN), skin (actinic keratosis), oropharynx (late Barrett's esophagus), lung (squamous metaplasia with dysplasia in bronchial mucosa), colon (premalignant adenoma), and prostate (high-grade prostate intraepithelial neoplasia, HGPIN) [128-133]. Microscopic metastases are also present in many cancer patients who are undergoing tumor resection with curative intent. For example, 25\% of colon cancer patients eventually develop hepatic metastases after primary tumor resection emerging from preangiogenic lesions that were present at the time of surgery [134-136]. By suppressing tumor neovascularization at subclinical stages, tumor progression and metastatic growth may be halted.

4.2. Superiority of Early Therapy and Sustained Angiogenesis Suppression. Animal studies have demonstrated that early administration of angiogenesis inhibitors is highly efficacious. The drug TNP-470 (O-[chloroacetyl-carbonyl] fumagillol) is a potent antiangiogenic analog of the antibiotic fumagillin $[124,137]$. A rat model of liver metastasis using $\mathrm{K} 12 / \mathrm{TRb}$ rat colon adenocarcinoma cells was employed to study the differential efficacy of early, early prolonged, or delayed administration of TNP-470 $(15 \mathrm{mg} / \mathrm{kg})$ on metastatic burden and survival [134]. Treatment initiated at d1 after tumor inoculation (early intervention) and maintained for $28 \mathrm{~d}$ (prolonged therapy) led to a $46 \%$ reduction in liver metastases and improved survival time compared to controls $(P=0.011)$. Another study showed a superior reduction in metastases with early ( $\mathrm{d}$ 0-6) compared to delayed ( $\mathrm{d}$ 7-13) TNP-470 treatment in rabbits bearing VX2 carcinoma [138].

The effect of TNP-470 on subclinical disease has also been elegantly studied by Shusterman and colleagues [139]. In the first study, xenografts of human neuroblastomaderived CHP-134 were implanted into athymic $(n u / n u)$ mice, with initiation of antiangiogenic treatment $12 \mathrm{~h}$ following grafting (early primary tumor model). Treated tumors were reduced by $90 \%$, compared to control animals. The second study involved administration of TNP-470 $12 \mathrm{~h}$ following
TABLE 5: Chemopreventive agents that possess antiangiogenic properties.

Alpha-difluoromethylornithine (DFMO)
Aspirin
Brassinin
Celecoxib
Curcumin
$1 \alpha, 25$-dihydroxyvitamin D3
Ellagic acid
Epigallocatechin 3-gallate
Finisteride
Genistein
N-acetylcysteine (NAC)
Naringenin
Oltipraz
Resveratrol
Retinoids
Selenium
Silymarin
Statins
Sulindac
Tamoxifen
Source: Angiotracker, The Angiogenesis Foundation
(http://www.angio.org/).

tail vein injection of CHP-134 cells into SCID/Beige mice (metastatic model). Autopsy of saline-treated control mice showed neuroblastoma deposits in the kidney, liver, adrenal gland, and ovaries in 75\% of subjects, whereas TNP-470treated mice showed no evidence of metastases. A third study evaluated TNP-470 effects in mice whose tumors were initially $0.35 \mathrm{~mm}^{3}$, but then became difficult to palpate following $10 \mathrm{~d}$ of cyclophosphamide treatment (minimal residual disease model). TNP-470 was then administered subcutaneously. Tumor growth was suppressed in the TNP470 -treated group by $82 \%$, compared to saline-treated controls. Histopathological analyses showed increased apoptosis by TdT-mediated nick-end labeling (TUNEL) assay in treated animals, but no with difference in tumor cell proliferation by Ki-67 assessment [90, 139]. These data demonstrate the importance of timing in antiangiogenic therapy and its efficacy in subclinical disease.

4.3. Evidence for Antiangiogenic Cancer Prevention. Cancer chemoprevention is defined as the use of pharmacological, natural, or dietary agents to inhibit the development of invasive cancer by blocking DNA damage caused by carcinogens or by arresting the progression of premalignant cells after damage has already occurred [4]. Angiogenesis inhibition blocks carcinogenesis by preventing progression to the invasive phenotype $[111,140,141]$. A number of well-known chemopreventive agents have antiangiogenic properties in vivo and in vitro (see Table 5). These include retinoids, vitamin D3, tamoxifen, oltipraz, curcumin, linoleic acid, ellagic 
acid, selenium, $\alpha$-difluoromethylornithine (DFMO), $N$ acetyl-l-cysteine (NAC), catechins, and celecoxib [142-151]. Classical angiogenesis assay systems, such as the chorioallantoic membrane assay (CAM), the corneal micropocket assay, and modified rat aortic ring assay, have been used to screen for biological activity of established chemopreventive agents $[152,153]$. Known angiogenesis inhibitors such as endostatin have also been shown to suppress carcinogen-induced tumor development in rodent models [154]. The antiangiogenic properties of select chemopreventive molecules shall be discussed.

\subsection{Antiangiogenic Factors in Dietary Sources}

4.4.1. Green Tea Catechins. After water, tea is the second most popular liquid in the world, and its consumption is linked with a decreased risk of colon, prostate, lung, esophageal, and other cancers [155-157]. Laboratory studies have demonstrated that green tea and its catechins prevent mutagenesis, tumorigenesis, cancer invasion and metastases, and angiogenesis [158-163]. Polyphenol catechins in tea, predominantly flavanols, possess chemopreventive and antiangiogenic activity. Epigallocatechin-3-gallate (EGCG) is a potent tea flavonoid that specifically inhibits endothelial cell proliferation stimulated by bFGF and induces avascular zones in the chick CAM assay. Mice that consume $1.25 \%$ green tea (human equivalent of drinking 2-3 cups of tea/day) show inhibition of VEGF-stimulated corneal neovascularization by as much as $70 \%$ and reduction of tumor cell invasion by $50 \%$ [163]. Green tea solution $0.6 \%$ administered to mice as the sole source of drinking fluid results in less tissue VEGF expression seen by immunostaining and lower microvessel density in lung adenomas, as well as significantly fewer tumors induced by the NNK carcinogen [162].

The molecular mechanism of EGCG is the result of its inhibition of urokinase and two gelatinases (MMP-2 and -9) involved in vascular as well as tumor invasion $[164,165]$. The MMP inhibitory activity is independent of zinc or calcium binding by EGCG. High doses of EGCG induce apoptosis when topically applied to SKH-1 hairless mice bearing UVBinduced squamous cell carcinomas [166]. Clinical trials are underway in Western and Asian nations to study the chemopreventive potential of green tea for oral, prostate, skin, and other cancers.

Preliminary data from these trials suggest clinical efficacy. An Italian study involving men with high-grade prostate intraepithelial neoplasia (HGPIN) demonstrated a protective effect from consuming daily green tea catechins over the course of a single year [167]. The double-blind, placebocontrol study randomized sixty men with HGPIN into a treatment arm receiving $600 \mathrm{mg}$ of purified green tea catechins (equivalent to 2-3 cups of tea/day) and a placebo $\mathrm{arm}$. The men were followed for one year, at which point they underwent prostate mapping via core needle biopsies. Based on those biopsy results, $30 \%$ of the placebo group progressed to prostate cancer, while the treatment arm demonstrated an impressively low progression rate of $3 \%$. Similarly, a Japanese interventional study of patients with recently removed colonic adenomas demonstrated that participants drinking an average of 12 cups equivalent of green tea polyphenols, obtained through both purified extracts and whole tea, had a 50\% reduction in risk of adenoma recurrence compared to patients who drank an average of six cups of green tea [168]. Chemopreventive effects in humans have also been observed through experimental trials involving the treatment of precancerous oral and cervical lesions $[169,170]$.

Polyphenon E, an extract from green tea leaves containing a defined mixture of polyphenolic catechins, is in clinical trials for prostate, bladder, esophageal, lung, head and neck cancers, and leukemia. In topical form, Polyphenon E 15\% ointment was approved by the U.S. FDA in 2006 as a treatment for external genital warts, which is considered an angiogenic neoplasm and a precursor to cervical cancer [171].

4.4.2. Genistein. Genistein (4',5,7-trihydroxyisoflavone), an isoflavonoid found in soybeans, has both chemopreventive and antiangiogenic activity. It suppresses carcinogenesis in a variety of animal models of mammary and prostate carcinoma following oral and parenteral administration [172-174]. Multiple antitumor mechanisms of action have been identified, including angiogenesis inhibition, induction of apoptosis, G2 cell cycle arrest, inhibition of c-fos expression and NF- $\kappa$ B activation, modulation of sex steroid receptors and growth factor signaling pathways [175-177]. Genistein inhibits angiogenesis by the following mechanisms: inhibition of bFGF- and VEGF-driven endothelial cell proliferation, migration, and tube formation; inhibition of extracellular matrix degradation by suppression of bFGFinduced endothelial production of plasminogen activator (PA) and plasminogen activator inhibitor (PAI); and suppression of receptor tyrosine kinase activity for VEGF, EGF, and PDGF $[178,179]$.

The antiangiogenic activity of genistein was initially detected in a study of healthy Japanese individuals who consumed a traditional soy-rich Japanese diet [180]. Urine from these subjects was collected, fractionated, and examined for activity to inhibit bFGF-stimulated endothelial cell proliferation. Of two fractions with antiendothelial activity, one contained genistein, daidzein, and $O$-desmethylangolensin. The impact of dietary soy intake was significant. In men who consumed a Japanese versus Western diet, urinary genistein was $7052 \mathrm{nmol} /$ day compared to $184.4 \mathrm{nmol} /$ day, respectively [181]. Soy intake has been shown to be inversely associated with cancer risk. Historically, breast cancer incidence rates have been 4 to 7 times higher among white women in the US compared to in women in China or Japan. However, when Asian women migrate to the US, their breast cancer risk rises over several generations to reach that of US white women, suggesting that modifiable factors, such as diet, rather than genetics, are responsible for the international differences. A study of over 73,000 women in China showed that daily intake of soy products such as soy milk, tofu, and fresh soybeans decreased premenopausal breast cancer risk [182]. Likewise, American women of Asian descent who consume a traditional soy-based diet have a low incidence of breast 
cancer $[178,183]$. Early soy intake ( $>1.5$ times per week) during childhood was found to reduce later breast cancer risk by $58 \%$ in a study of Asian women in California and Hawaii [184]. Similarly, Japanese men in Hawaii who consume a high soy diet have low mortality from prostate cancer, although the incidence at autopsy of in situ prostate neoplasia is similar to men in Western societies [185]. Based on laboratory findings and epidemiological data, genistein and a manufactured derivative known as genistein-concentrated polysaccharide (GCP), are being evaluated in prevention trials for prostate cancer [186].

Such clinical studies have helped dispel the theoretical concerns that soy intake may worsen breast cancer or interact with tamoxifen treatment due to the fact that genistein is a phytoestrogen. In fact, among women with breast cancer, soy food consumption has now been shown in numerous, largescale studies to be significantly associated with decreased risk of death and recurrence, regardless of estrogen receptor status or tamoxifen use [187].

4.4.3. Resveratrol. Resveratrol $\left(3,4^{\prime}, 5\right.$-trihydroxystilbene) is a natural phytoalexin and polyphenol found in more than 72 plant species, such as mulberries, peanuts, grapes, and grape products, including red and rose wine. Fresh grape skins contain 50-100 $\mu \mathrm{g}$ resveratrol per $\mathrm{g}$ and yield a concentration in Italian red wine of $1.5-3 \mathrm{mg} / \mathrm{L}$ [188]. White wine contains minimal levels of resveratrol. Resveratrol inhibits angiogenesis in the chick CAM assay, suppresses VEGF- and bFGF-induced corneal neovascularization (at 3$4 \mathrm{mg}$, equivalent to 3-4 glasses red wine/day), and inhibits tumor vascularization in T241 fibrosarcoma growing in mice [189]. Resveratrol also inhibits chemically induced mammary carcinogenesis, skin cancer tumorigenesis, and tumor growth and metastasis in mice bearing Lewis lung carcinoma [188, 189]. In mice with full thickness skin wounds, resveratrol delays wound healing angiogenesis and the time required for complete wound closure [190]. A number of antiangiogenic mechanisms have been identified, including suppression of capillary tube formation inhibition of endothelial cell DNA synthesis and binding of VEGF to human endothelial cells reduction of vascular cell adhesion molecule-1 (VCAM-1) interference with phosphorylation of endothelial mitogen-activated kinases; suppression of COX2 enzyme and inhibition of MMP-9 expression [189, 191193].

Red wine in particular has been repeatedly shown to have protective effects in large population studies. The California Men's Health study of over 84,000 men demonstrated an inverse relationship between red wine consumption and lung cancer incidence. Notably, there was a $61 \%$ risk reduction for men drinking at least one glass of red wine per day [194]. This protective benefit for lung cancer with greater than one glass per day was replicated in a Spanish population, using a case-control methodology involving hospitalized lung cancer patients [195]. Additionally, the Health Professionals Followup Study identified a protective effect for prostate cancer with a $36 \%$ risk reduction in men drinking 2-4 glasses of red wine per week [196].
4.4.4. Lycopene. Lycopene, a type of natural pigment in the carotenoid family, gives tomatoes and other fruits such as watermelon and papayas their bright red color. Lycopene is an angiogenesis inhibitor which suppresses signaling by PDGF and Platelet Activation Factor in vitro [197]. In animal studies, lycopene suppresses spontaneous mammary tumors, hepatocarcinogenesis, colonic crypt foci, prostate cancer, and hepatoma metastases [198].

Two interventional studies have also demonstrated potent biologic effects of lycopene in the setting of malignancy. In one study, 32 men who were recently diagnosed with early-stage prostate cancer were instructed to eat one meal per day incorporating commercially made tomato sauce containing $30 \mathrm{mg}$ of lycopene for 3 weeks. They then underwent curative prostatectomy; pathologic examination of the resected tissue showed a 3 -fold increase of lycopene concentration in the prostate tissue, along with a slight decrease in blood prostate-specific antigen (PSA) level [199]. In a separate study, 41 men with recurrent prostate cancer were asked to consume a tomato-rich diet to achieve a minimum lycopene intake of $25 \mathrm{mg} /$ day along with $40 \mathrm{~g} /$ day of soy protein for a total of 8 weeks. While the study design made it difficult to separate the dietary effects of lycopene from soy, it is notable that the mean serum VEGF levels of all the subjects was reduced from 87 to $51 \mathrm{ng} / \mathrm{mL}$ in a statistically significant way, and that $34 \%$ of the men experienced reduced PSA levels [200].

In the Health Professionals Follow-Up Study of over 51,000 men, the highest quintile of lycopene consumption was found to have a $15 \%$ risk reduction for developing prostate cancer compared to men in the lowest quintile [201]. The risk reduction was even greater if tomato sauce was ingested; men consuming more than 2 servings/week had a nearly $23 \%$ risk reduction compared to men consuming less than 1 serving/month.

4.4.5. Omega-3 Polyunsaturated Fatty Acids (PUFAs). Omega-3 fatty acids are unsaturated fatty acids that are vital for normal metabolism but cannot be synthesized by the human body. The best known sources of the longchain omega-3 fatty acids-docosahexaenoic acid (DHA) and eicosapentaenoic (EPA) - are cold water oily fish such as salmon, herring, mackerel, anchovies, sardines, and trout. Both preclinical and epidemiological studies suggest that omega-3 PUFAs are effective cancer preventative agents. Omega-3 PUFAs inhibit angiogenesis by downregulating angiopoietin-2 and may competitively inhibit the bioconversion of omega-6 PUFA's into their angiogenesis-promoting derivatives such as prostaglandins and arachidonic acid [202]. In contrast, omega-6 PUFAs, present at high levels in sunflower oil, peanut oil, and corn oils, have been shown in vitro to stimulate endothelial migration and tube formation. Furthermore, omega-3 PUFAs have been shown to suppress Akt/m-TOR signaling pathway [203]. In animal models, Omega-3 fatty acids have been shown to suppress a variety of tumors and to prevent osteolytic metastastic lesions in bone from breast cancer [204]. 
Intake of omega-3 PUFAs from seafood has been associated with a decreased risk for certain cancers, including pancreatic, colon, breast, and prostate cancer. In a casecontrol study of 532 people diagnosed with pancreatic adenocarcinoma, consumption of omega-3 fatty acid of at least $0.85 \mathrm{~g} /$ day was associated with a decreased risk of pancreatic cancer; those with the highest intake had a 30\% risk reduction [205]. A meta-analysis of fish intake and prostate cancer in case-control and cohort studies revealed no association between fish consumption and prostate cancer incidence, but showed a significant $63 \%$ reduction in prostate cancer mortality [206].

4.4.6. Glucosinolates, Isothiocyanates, and Indole-3-carbinol. Cruciferous vegetables - which include cabbage, broccoli, cauliflower, collard greens, mustard greens, radishes, Brussel sprouts, bok choy, and kale-are rich in glucosinolates, a mustard oil glycoside that imparts a spicy, bitter flavor. The enzyme myrosinase-stored in a separate compartment of the plant cell and liberated when the plant is crushed-converts glucosinolate to the bioactive molecules isothiocyanate and indole-3-carbinol, both of which are antiangiogenic. Sulforaphane, a type of isothiocyanate, acts through inactivation of hypoxia inducible factor-1 alpha, activation of FOXO transcription factors, and promotion of endothelial cell apoptosis [207-209]. Indole-3-carbinol inhibits endothelial cell proliferation, tube formation and induces apoptosis $[210,211]$.

Epidemiological evidence suggests that regular dietary intake of cruciferous vegetables may lower the risk of developing several cancers. A major prospective dietary study, the European Prospective Investigation into Cancer and Nutrition (EPIC), followed the dietary habits and health of 521,468 subjects in 10 European countries between 1991-2000 [212]. After an average followup of 8.7 years, 1,830 people were diagnosed with lung cancer. Regular consumption of cauliflower and cabbage by current smokers was associated with a $23 \%$ reduction in the risk for squamous cells carcinoma of the lung. The study also found an almost $50 \%$ reduced risk of cancer of the upper digestive tract (oral cavity, pharynx, larynx, and esophagus) among people who ate the most cauliflower and cabbage ( $34 \mathrm{~g} /$ day) compared with those who ate the least ( $3 \mathrm{~g} /$ day) [213].

Another large prospective study of more than 35,000 women living in Iowa and followed for 20 years found a $18 \%$ reduced risk for non-Hodgkin's lymphoma (NHL) among women who had the highest consumption of cruciferous vegetables; in particular, consumption of at least 4 servings/month or broccoli was associated with a $28 \%$ risk reduction for non-Hodgkin's lymphoma [214]. In separate study of nearly 67,000 women in the Nurses' Health Study, more frequent dietary intake of broccoli (at least 2 servings/week) was associated with a 33\% risk reduction for ovarian cancer [215].

4.4.7. Flavonoids. Flavonoids are a family of polyphenols that serve as important plant pigments. Their natural roles may include acting as photoprotectants, antimicrobials, deterrents against herbivores, as well as attractants to pollinators and seed dispersant animals. They are subcategorized by chemical structure into flavones, flavonols (such as quercetin), anthocyanidins, proanthocyanidins, ellagic acid, ellagitannins, and isoflavones (such as genistein mentioned earlier), among others. In contrast, the term flavanol specifically refers to the catechins, mentioned earlier.

Flavonoids in fruits and vegetables include quercetin, anthocyanidins, proanthocyanidins, ellagitannins, among others. Flavonoids are antiangiogenic through a variety of mechanisms; they inhibit VEGF expression, inhibit endothelial cell migration, and decrease matrix metalloproteinases MMP-2 and MMP-9 [216-220]. The U.S. Department of Agriculture identifies spinach, onions, parsley, beets, and thyme among high flavonoid-containing vegetables and herbs [221]. Fresh salad greens such as lettuce, chicory, arugula, and red lettuce are also rich in polyphenolic flavonoids [222].

Quercetin. Quercetin is a flavonoid found in numerous types of fruits and vegetables. Its antiangiogenic properties include inhibition of MMP-2 and MMP-9 secretion from tumor cells and inhibition of endothelial cell proliferation and migration [219]. For example, quercetin has been shown to reduce in vitro tube formation of VEGF-stimulated human umbilical vein endothelial cells (HUVECs) grown on a 3dimensional matrix by as much as $40 \%$ [220]. With regards to epidemiologic data, a large prospective study of 41,000 women living in Iowa between the ages of 55 and 69 found a number of flavonoid-containing leafy greens, which are abundant in quercetin, was associated with a significant risk reduction for lung cancer [223]. Women who reported eating more than six servings of leafy greens per week were nearly half as likely to develop lung cancer during the four-year follow-up period, when compared to women who ate the least greens. This benefit extended to both smokers and nonsmokers alike.

One of the richest sources of dietary flavonoids is red onion, which has particularly high levels of quercetin. Case control studies from Italian and Swiss populations have shown that moderate (1-7 servings/week) to high frequency (>7 servings/week) of onion consumption protects against a variety of cancer including colorectal, prostate, ovarian, and laryngeal cancers [224]. For example, there was a nearly $73 \%$ risk reduction for ovarian cancer in the population when comparing those who frequently consumed onion (>7 servings/week) compared to those with less frequent consumption $(<1$ serving/week). Similarly, there was an $88 \%$ risk reduction for esophageal cancer in the group with highest versus lowest onion intake. In a separate Dutch cohort study, consumption of at least half an onion/day was associated with $50 \%$ risk reduction in gastric cancer [225]. Finally, researchers using data from the large-scale EPIC study showed that high onion consumption was associated with a $21 \%$ risk reduction for ovarian cancer [226].

Anthocyanins. Anthocyanins are pigments that are present in many types of berries and grapes as well as red wine. 
They exhibit a purple color at neutral $\mathrm{pH}$, red in acidic, and blue in alkaline conditions. Anthocyanins are end-products of the flavonoid pathway, while anthocyanidins are their aglycone precursors. Their natural function may be to attract pollinators and animals to eat the fruit or plant and disperse their seeds.

They have been shown to inhibit angiogenesis and tumor growth in experimental animals injected subcutaneously with N-nitrosomethylbenzylamine (NMBA), an esophageal carcinogen [227]. Rats that were fed an anthocyanin-rich freeze-fried extract ( $5 \%$ in diet) obtained from black raspberries (BRB), blackberries, or strawberries showed a reduced number of esophageal tumors as compared to controls $-41 \%$ less by BRB, $46 \%$ less by blackberries, and $24 \%$ less by strawberries [228]. In another study of esophageal papillomas in rats, animals fed BRB had fewer papillomas that were of smaller volume, with reduced cell proliferation and suppression of VEGF and HIF-1alpha expression seen by immunohistochemistry as compared to the non-BRB treated mice $[229,230]$. DNA microarray studies of rat esophageal carcinogenesis have shown that dietary black raspberries modulate the expression of genes associated with angiogenesis, including the cyclooxygenase and lipoxygenase pathways of arachadonic acid metabolism, as well as MMP10 expression; CD34 staining as a marker for microvessel density was also found to be significantly reduced in the BRB diet animals [228, 229]. Berries are also rich in other natural polyphenols such as ellagic acid, which contributes to bioactivity.

An extract from black raspberries has been studied in human subjects diagnosed clinically with oral intraepithelial neoplasia. BRB 10\% was applied in a gel form to the oral mucosa four times daily. After 6 weeks, there was reduced histological grade of dysplastic lesions in $50 \%$ of treated subjects, and reduced levels of COX-2 and iNOS in the lesions [231].

Proanthocyanidins. Proanthocyanidins are a type of tannin-large polymeric chains of flavonoids - found in many plants and fruits, notably cacao, cinnamon, cranberry, apples, grapes, black current, chokeberry, and persimmon. Proanthocyanidins are thought to be the major source of flavonoids ingested in the Western diet [232]. Historically tannins from wood bark were used as tanning agents to turn animal hide into leather due to their ability to precipitate proteins. They are also responsible for the astringent taste of certain foods and beverages [233]. Among their natural roles is protection against predation [234]. Anthocyanins and proanthocyanidins share steps in the flavonoid biosynthetic pathway. Specifically, proanthocyanidins are generated from the polymerization of flavonoid monomers, which are products of a branch pathway of anthocyanin biosynthesis.

Proanthocyanidins constitute $60 \%$ of the polyphenol content in cacao, the source of chocolate [235]. It is in the yeast-based fermentation of the raw cacao bean where the characteristic flavor precursors develop and polyphenols complex into procyanidin polymers with a core structure of (-)-epicatechin, similar to green tea [236]. Pentameric and octameric procyanidins isolated from cacao beans have been shown to inhibit the growth of cultured human aortic endothelial cells and human dermal microvascular endothelial cells (HDMECs) following angiogenic stimulation with low-level $\mathrm{H} 2 \mathrm{O} 2$ [237]. The cacao pentameric fraction downregulates the expression of ErbB2 tyrosine kinase. Cocoa powder extract inhibits TNF-alpha-induced VEGF secretion in vitro. When JB6 mouse epidermal cells were pretreated with a polyphenol-rich cocoa powder extract, then exposed to TNF-alpha, there was a dosedependent inhibition of TNF-alpha-induced VEGF expression compared to untreated controls [238]. At the highest but noncytotoxic concentration of cacao extract, VEGF expression was reduced more than twofold compared to controls.

There is evidence that cacao consumption can affect human vasculature and health. After ingestion, cacao flavonoids are stable in the gastric environment and can be detected in human plasma [239]. In studies of human volunteers, angiotensin-converting enzyme (ACE) activity is inhibited by $18 \%$ only three hours after a single intake of 75 grams of dark (72\% cocoa) chocolate [240]. In a study of 4,849 individuals in Italy, those who ate one 20 gram serving of dark chocolate every 3 days had serum C-reactive protein (CRP) significantly lower than those who did not [241]. Notably, the Kuna Indians living on the San Blas Island of Panama-who have a ten-fold higher dietary intake of cacao compared to Panamanian mainlanders-have lower blood pressure, live longer, and have lower incidence of cancer compared to mainlanders [242]. Consistent with their cacao consumption, the Kuna have 6-times higher urinary excretion of cacao procyanidin metabolites than mainlanders [243].

Procyanidins are also found in cinnamon, which have been found to inhibit angiogenesis and tumor growth. Cinnamon extract inhibits VEGF receptor-2 on endothelial cells and suppresses endothelial cell proliferation, migration, and tube formation in vitro [244]. A water-soluble extract from dried cinnamon bark, orally administered every day or every other day for 20 days to mice bearing experimental melanomas suppresses melanoma growth [245]. The cinnamon extract suppressed tumor microvessel density, and as shown by quantitative RT-PCR, the expression of angiogenic factors VEGF, FGF, and TGF- $\beta$ as well as COX-2 and HIF-1alpha, which promote angiogenesis. In addition, the cinnamon extract suppresses melanoma metastasis as measured by the size and weight of the spleen and draining lymph nodes of mice bearing melanoma in vivo [245].

Many edible berries also contain proanthocyanidins, including the American cranberry, black currants, and grapes. Chokeberries, named because of their extreme astringency, contain among the highest levels of proanthocyanidins detected [246]. Mixtures of berry extracts inhibit tube formation of endothelial cells in Matrigel [247]. Extracts from blueberries, bilberries, raspberries, and strawberries suppress VEGF expression by immortalized human keratinocytes (HaCaT cells) in vitro and this VEGF inhibition appears to be independent of the antioxidant property of the extracts [247]. Experimental liver cancer in rodents induced by the carcinogen DENA are suppressed in 
number and size by an extract from black currants added to the animal's diet (equivalent to $500 \mathrm{mg} / \mathrm{kg}$ body weight) [248]. Procyanidins in cranberries may have multiple health benefits including both chemopreventive properties as well as maintaining bladder health due to inhibiting E. Coli adherence to uroepithelium [249]. A cranberry extract tested on DU145 human prostate cancer cells significantly inhibited expression of MMP-2 and MMP-9 and increased expression of TIMP-2 in vitro, consistent with mechanisms that suppress angiogenesis [250]. Cranberry juice, given as a $20 \%$ solution, reduces the incidence of azoxymethane-induced colonic aberrant crypts in rats by $77 \%$ versus drinking water controls when supplemented for three weeks before and ten weeks after carcinogen exposure [251].

Both apples and apple juice are rich sources of procyanidins in addition to other polyphenols previously described such as quercetin and catechins. Based on the USDA Continuing Survey of Food Intakes by Individuals (CSFII), apples are a major source of proanthocyanidins in the U.S. diet [232]. In a recent study, scientists examined the specific chemopreventive properties of a polyphenol extract of apple juice. Apple procyanidins were found to inhibit Cox1 [252]. Several studies have shown that cloudy apple juices, such as apple cider, contain much higher concentrations of procyanidins than clear apple juices. Specifically, one study determined that the suspended particles in cloudy apple juice contain up to $60 \%$ of apple procyanidins in the juice.

Epidemiological studies have provided accumulating evidence that apples have cancer-preventive properties, particularly against lung and colorectal cancers. In the Nurses Health Study involving 77,000 women, a statistically significant $37 \%$ risk reduction for lung cancer was observed among women for increases of 1 serving per day of apples or pears [253]. Similar results were obtained from a Finnish cohort study involving 10,000 men and women [254]. The results of a case-control study conducted in Hawaii with 528 lung cancer cases and 528 controls found a statistically significant decrease in lung cancer risk with increased consumption of apples [255]. An analysis of case-control studies conducted in Italy found that people who consumed at least one apple per day had a significantly reduced risk of colorectal cancer and cancers of the oral cavity, larynx, breast, and ovary relative to those who ate less than an apple a day [256]. In a prospective cohort of 35,159 Iowa women aged 55-69 years, intake of apple juice or cider was associated with lower risk of developing non-Hodgkin's lymphoma [214].

Ellagitannins. Ellagitannins are glycosides of the flavonoid ellagic acid and fall under the category of hydrolyzable tannins. They can be found in numerous types of fruits and nuts including pomegranate, strawberries, blackberries, raspberries, muscadine grapes, walnuts, and pecans [257]. Upon consumption, ellagitannins are hydrolyzed to ellagic acid which is antiangiogenic. Colonic microbiota further convert ellagic acid to urolithin A which is also bioactive [258].

All parts of the pomegranate contain high levels of ellagitannins, of which the primary type is punicalagin. Bioactive polyphenols are found not only in the edible aril (pulp and seed) which is popularly consumed, but also concentrated in the peel of the fruit, which is not usually consumed but may be part of the juice extraction by some processors. Indeed, polyphenol extraction increases 6.5-fold when the whole fruit is processed compared to juice from arils alone [259]. Ellagitannins have been shown to inhibit the growth of prostate cancer in both in vitro and in vivo laboratory experiments, and studies have suggested that the compound's antiangiogenic properties play a role in this inhibition. Interestingly, pure pomegranate juice has been found to be more potent than its separated individual polyphenol components, likely due to synergistic effects [260]. Effects of pomegranate extract (POMx)—-derived from the skin and seeds of the pomegranate fruit-have been shown on endothelial cells (HUVECs) and human prostate cancer cells (LNCaP line) in vitro [261]. Pomegranate extract inhibited the proliferation of both cell types and suppressed the secretion of VEGF and HIF-1alpha. Mice implanted with human prostate tumors derived from the LAPC4 tumor line were administered the human equivalent of 1.7 cups $(8 \mathrm{oz})$ of pomegranate juice per day. Pomegranate juice significantly decreased tumor microvessel density, as well as tumor size, compared to the control animals [261]. Pomegranate juice, when given as a $20 \%$ solution, reduces the incidence of azoxymethane-induced colonic aberrant crypts in rats [251]. In a study of men with recurrent prostate cancer who drank 1 cup of pomegranate juice per day, their prostate-specific antigen (PSA) doubling time was extended from 15 to 54 months [262].

4.4.8. Menaquinone. A form of vitamin $\mathrm{K}$, menaquinone (vitamin K2), found in certain food sources is antiangiogenic and associated with a reduced risk for developing several forms of cancer. Menaquinone is distinct from the phylloquinone (Vitamin K1) present in dark leafy vegetables. Instead, menaquinone is a fat-soluble vitamin formed naturally by bacteria in fermented dairy products, including cheese and yogurt, in fermented soy such as natto, and also present in dark meat. Certain cheeses, such as Dutch Gouda, Swiss Emmental, and Norwegian Jarlsberg, have particularly high concentrations of menaquinone. In laboratory studies, menaquinones suppress angiogenesis, enhance tumor apoptosis, and inhibit the proliferation of cancer cells [263].

A subpopulation of the European Prospective Investigation into Cancer and Nutrition (EPIC) study, called the Heidelberg cohort, followed the diet and health status of more than 24,300 participants for at least ten years, starting in 1994. The participants answered detailed questionnaires at regular intervals about their diet and general health. During the follow-up period, 1,775 cancer cases were diagnosed, of which 458 were fatal. Among the foods documented, participants who consumed the most cheese (at least $41 \mathrm{~g} /$ day) had a significantly reduced risk of dying from cancer compared with those who consumed the least (less than $14 \mathrm{~g} /$ day) [264]. Cheese consumption contributed to about $45 \%$ of total menaquinone intake. In terms of specific cancers, higher consumption food containing menaquinone was associated with significantly lower 
incidences of lung cancer and prostate cancer. Participants with the highest levels of menaquinone in their diets had a $62 \%$ reduced risk of lung cancer compared with those with the least, and a similar reduced risk of dying from lung cancer.

Prospective clinical studies of vitamin K2 have shown chemopreventive activity in patients. In a study of 40 women in Osaka diagnosed with viral liver cirrhosis, individuals were assigned randomly to an intervention or control group. During more than 7 years of followup, the cumulative proportion of people who developed hepatocellular carcinoma (HCC) was significantly smaller in the group that received vitamin K2 (45 mg/day) [265]. Vitamin K2 decreased the risk of HCC to $20 \%$ compared to that of the control group. On an annual incidence basis, HCC developed in only $1.6 \%$ in the treatment group compared with $8.8 \%$ in the control group and $7.9 \%$ in the general cirrhotic population.

4.4.9. Curcumin. Curcumin (diferuloylmethane), a flavonoid derived from the plant Curcuma longa, is present in tumeric spice. It has chemopreventive and antiangiogenic activity and inhibits carcinogenesis in skin, stomach, intestines, and liver. Dietary ingestion of curcumin has been shown to prevent the formation of colon polyps, suppress proliferation of colon cancer and prostate cancer cells, and decrease intratumoral microvessel density [266-268]. Studies of endothelial cells exposed in vitro to curcumin show induction of apoptosis; downregulation of gene transcripts for VEGF, bFGF, and MMP-2; COX-2 inhibition; upregulation of TIMP; disruption of vascular tube formation; and inhibition of endothelial cell motility by interfering with the Ras-mediated c-Jun N-terminal kinase (JNK) pathway [269273].

A Phase I prevention trial of curcumin (500-800 mg/day) showed histological improvement of lesions in patients with various malignant and premalignant lesions, including recently resected bladder cancer, oral leukoplakia, intestinal metaplasia, CIN, and Bowen's disease [274]. In a Phase II study, dietary curcumin was given for 30 days to 44 subjects with aberrant crypt foci (ACF), a premalignant marker for colorectal cancer. Those who consumed $4 \mathrm{~g}$ /day of curcumin had a $40 \%$ reduction in the number of rectal ACF lesions [275].

4.4.10. Beta-cryptoxanthin. Beta-cryptoxanthin is a natural carotenoid pigment present in brightly colored orange, red, or yellow foods. Structurally it is related to betacarotene, and is ultimately metabolized to vitamin A in the body and can be found circulating in the blood after consuming carotenoid-rich foods. Vitamin A and retinoic acid analogs are antiangiogenic and synthetic derivatives have been investigated as chemopreventive agents [276-280].

Papaya is a rich source of carotenoids, with the same lycopene content as tomatoes, but twice the betacryptoxanthin content. Studies in tropical populations have shown that increased daily consumption of papayas results in higher levels of beta-cryptoxanthin in the blood [281]. Consumption of such beta-cryptoxanthin-rich foods may reduce cancer rates in high-risk populations. For example, higher papaya consumption has been shown to be inversely associated with the risk of developing high-grade cervical lesions. A nested case control study involving a population of HPV-positive women in Brazil showed that consuming one or more servings of papaya per week cut the risk of developing a high grade cervical lesion by $81 \%$ [282].

Other studies have shown a risk reduction with the consumption of papaya and carotenoid-rich fruits for other cancers, including lung and gall bladder cancers [283, 284]. In the Singapore Chinese Health Study, 63,257 Chinese men and women ages 45-74 participated in a prospective study of diet and cancer [284]. Using a food composition database, an estimate of their carotenoid intake, including beta-cryptoxanthin was quantified. In the first 8 years of follow-up, 482 lung cancer cases occurred in the cohort. A high level of dietary beta-cryptoxanthin was associated with reduced risk of lung cancer. Comparing the highest to lowest quartile, there was a $27 \%$ risk reduction among all subjects, and a $37 \%$ risk reduction among current smokers.

In a study of women, diet, and breast cancer risk, 403 breast cancer cases and 602 controls from the Nurses' Health Study were examined for high breast densities, a strong predictor for breast cancer risk [285]. Overall, circulating total carotenoids were inversely associated with breast cancer risk. Among women in the highest tertile of mammographic density, total carotenoids were associated with a $50 \%$ reduction in breast cancer risk.

4.4.11. Other Novel Dietary Inhibitors. We have identified antiangiogenic activity in a number of other dietaryderived chemopreventive molecules. These include brassinin, a phytoalexin found in Chinese cabbage; the citrus-derived bioflavonoids hesperidin and naringenin; ellagic acid from berries, pomegranate, and grapes; silymarin from milk thistle and artichoke; and the organosulfur allyl disulfide derived from garlic [286-291]. Further studies are underway to define their molecular targets in angiogenesis, their optimal biological doses, and efficacy in inhibiting tumor vascularity.

The diverse natural sources of these and other antiangiogenic chemopreventive molecules raise the possibility of designing scientific diets for patients at high risk for cancer, or for those with known disease to chronically suppress angiogenesis and tumorigenesis.

\section{Conclusion and Future Directions}

Angiogenesis is a critical, rate-limiting step in the development of all known cancers, and its inhibition suppresses tumor growth, progression, and metastases. Antiangiogenic therapy represents a new approach to the early intervention and prevention of malignant disease. During the next two decades, the total yearly number of newly diagnosed cases of cancer is projected to rise from 12.4 million new cases per year in 2008 to 26.4 million in 2030 , and the number of annual deaths is projected to increase $170 \%$, to 17 million [292, 293]. According to the World Health Organization 
and International Agency for Research on Cancer, cancer is the leading cause of death worldwide as of 2010 [293]. The implementation of effective chemoprevention strategies based on angiogenesis inhibition attained through dietary sources may decrease these numbers in a cost-effective and quality of life enhancing manner. Dietary effects are already thought to underlie many of the large international differences in incidence seen for most cancers [294]. Indeed, nutritional factors have been estimated to contribute to 20 $60 \%$ of cancers worldwide and to approximately one-third of deaths from cancer in Western countries [295].

The identification of dietary sources of antiangiogenic molecules has been aided tremendously through observational epidemiologic studies, which have the ability to identify specific foods associated with reduced cancer risk. These studies generally fall under the categories of prospective cohort and retrospective case-control studies, and more of both of these types of studies will be necessary to identify additional sources of antiangiogenic compounds and to help confirm the chemopreventive properties of previously identified foods and their constituent bioactive molecules.

The dietary prospective cohort study allows thorough assessment of dietary exposures with a reduced risk of recall bias as patients are initially cancer-free when enrolled. As study participants are followed into the future and observed for the development of cancer and other cancer-related endpoints, investigators can identify specific foods present in participants' diets that are associated with cancer risk reduction. With the evolving understanding of the underlying molecular basis of various naturally antiangiogenic foods, an important consideration for future cancer prevention cohort studies will be to ensure accurate assessment of participants' dietary intake of bioactive compounds. This will include not only comprehensively querying participants about all potential dietary sources of the bioactive compounds of interest, but also obtaining more detailed information about the preparation of foods, as this can significantly impact the amount of antiangiogenic molecules obtained through diet. Furthermore, the subtypes of foods consumed, such as the specific variety of apple or tomato eaten by a participant, and the way the food is processed or cooked prior to consumption, can strongly affect the amount of consumed bioactive molecules and would be important information to collect. Thus, while the food frequency questionnaires (FFQs) used in past cohort studies have attempted to quantify the intake of various foods, future studies focused on antiangiogenesis may be able to make a more detailed and accurate assessment of this particular aspect of dietary intake.

Case-control studies can also be valuable as a method for expediently identifying promising dietary exposures without the need for the long timeframes and massive study populations that typically characterize dietary cohort studies. While case-control studies are nearly always vulnerable to recall bias on the part of the cancer patients who compose the case populations, they are a valuable starting point in identifying promising risk-reducing foods that can be further explored through prospective and, more recently, interventional dietary studies. The key to these studies will be the use of well-designed dietary survey instruments and methods to allow data capture on short time horizons that can accurately gauge the intake of antiangiogenic and chemopreventive biomolecules. Finally, interventional dietary studies are a particularly promising methodology with which to confirm the antiangiogenic and chemopreventive properties of specific foods and bioactive molecules. In particular, recently diagnosed cancer patients or those with pre-invasive angiogenesis-dependent lesions such as colonic adenomas, prostatic intraepithelial neoplasia, cervical intraepithelial neoplasia, and actinic keratoses could potentially show significant benefit from short-term antiangiogenic dietary interventions with regards to progression, metastasis, or recurrence of their lesions [167]. Investigators with access to serum or biopsy samples could also follow changes to angiogenesis biomarkers, tumor biomarkers, or tumor characteristics $[262,296]$. Because of their experimental nature, randomized interventional dietary studies have the potential to become a valuable method for validating the antiangiogenic nature of bioactive molecules and foods.

The United States Department of Agriculture's update to its longstanding Food Pyramid dietary recommendationsnamely, its replacement with the new MyPlate initiative that pushes for an increase in the amount of whole fruits and vegetables consumed at each meal-does appear to indirectly promote increased consumption of certain foods that contain natural sources of antiangiogenic molecules [297]. For example, specific recommendations of the initiative include glucosinolate-rich cruciferous vegetables, lycopenecontaining tomatoes, resveratrol-bearing grape products, and beta-cryptoxanthin-abundant orange and yellow vegetables.

Data and conclusions from rigorous dietary cancer prevention studies should be implemented into public health policy. Optimal health outcomes result not just from high quality medical care, but also from diet and lifestyle patterns that can intercept disease at the earliest microscopic stages. Investments in cancer prevention, guided by the biological principles of antiangiogenic therapy, will expand on the substantial clinical applications already established by the biopharmaceutical industry. Cancer prevention using antiangiogenic factors present in widely available foods further offers an egalitarian strategy for large populations in societies that increasingly recognize the value of healthpromoting dietary choices. Many dietary sources of angiogenesis inhibitors are common ingredients in the world's most popular culinary traditions (i.e., Asian, Mediterranean, etc.). We propose that an antiangiogenic diet is a practical and cost-effective method to reduce the risk of cancer and other diseases and to enhance quality of life.

In summary, tumor angiogenesis is a critical target for cancer prevention. Natural antiangiogenic molecules are present in numerous dietary sources and represent a wide spectrum of mechanisms that can suppress the growth of microscopic tumors. The control of blood vessel growth through dietary antiangiogenesis promises to redefine cancer as a disease that can be suppressed throughout an individual's lifetime, from infancy through adulthood. 


\section{Acknowledgments}

The author would like to thank Erwin Kruger, Justin Leahey, and Joy Li for their assistance in research, data compilation, codification, and analysis.

\section{References}

[1] Global Action Against Cancer, World Health Organization and International Union Against Cancer, 2005, http://www .who.int/cancer/media/GlobalActionCancerEnglfull.pdf.

[2] "State bite: lifetime risk of being diagnosed with cancer," Journal of the National Cancer Institute, vol. 93, no. 10, p. 742, 2001.

[3] A. B. Mariotto, K. R. Yabroff, Y. Shao, E. J. Feuer, and M. L. Brown, "Projections of the cost of cancer care in the United States: 2010-2020," Journal of the National Cancer Institute, vol. 103, no. 2, pp. 117-128, 2011.

[4] Chemoprevention Working Group, "Prevention of cancer in the next millennium: report of the Chemoprevention Working Group to the American Association for Cancer Research," Cancer Research, vol. 59, no. 19, pp. 4743-4758, 1999.

[5] J. Folkman, "What is the evidence that tumors are angiogenesis dependent?" Journal of the National Cancer Institute, vol. 82, no. 1, pp. 4-6, 1990.

[6] J. Folkman, E. Merler, C. Abernathy, and G. Williams, "Isolation of a tumor factor responsible or angiogenesis," Journal of Experimental Medicine, vol. 133, no. 2, pp. 275$288,1971$.

[7] J. Folkman, "Tumor angiogenesis: therapeutic implications," The New England Journal of Medicine, vol. 285, no. 21, pp. 1182-1186, 1971.

[8] D. Ribatti, A. Vacca, and F. Dammacco, "The role of the vascular phase in solid tumor growth: a historical review," Neoplasia, vol. 1, no. 4, pp. 293-302, 1999.

[9] J. Folkman, "Angiogenesis in cancer, vascular, rheumatoid and other disease," Nature Medicine, vol. 1, no. 1, pp. 27-31, 1995.

[10] R. S. Kerbel, "Tumor angiogenesis: past, present and the near future," Carcinogenesis, vol. 21, no. 3, pp. 505-515, 2000.

[11] N. Weidner, "Angiogenesis as a predictor of clinical outcome in cancer patients," Human Pathology, vol. 31, no. 4, pp. 403405, 2000.

[12] J. Folkman, “Tumor angiogenesis," in Harrison's Textbook of Internal Medicine, E. Braunwald, A. S. Fauci, D. L. Kasper et al., Eds., pp. 132-152, McGraw-Hill, New York, NY, USA, 15th edition, 2000.

[13] M. H. Mangi and A. C. Newland, "Angiogenesis and angiogenic mediators in haematological malignancies," British Journal of Haematology, vol. 111, no. 1, pp. 43-51, 2000.

[14] K. A. Brandvold, P. Neiman, and A. Ruddell, "Angiogenesis is an early event in the generation of myc-induced lymphomas," Oncogene, vol. 19, no. 23, pp. 2780-2785, 2000.

[15] T. Padró, S. Ruiz, R. Bieker et al., "Increased angiogenesis in the bone marrow of patients with acute myeloid leukemia," Blood, vol. 95, no. 8, pp. 2637-2644, 2000.

[16] S. V. Rajkumar and P. R. Greipp, "Angiogenesis in multiple myeloma," British Journal of Haematology, vol. 113, no. 3, p. $565,2001$.

[17] G. Pruneri, F. Bertolini, D. Soligo et al., "Angiogenesis in myelodysplastic syndromes," British Journal of Cancer, vol. 81, no. 8, pp. $1398-1401,1999$.
[18] J. Rak, J. Filmus, and R. S. Kerbel, "Reciprocal paracrine interactions between tumour cells and endothelial cells: the 'angiogenesis progression' hypothesis," European Journal of Cancer Part A, vol. 32, no. 14, pp. 2438-2450, 1996.

[19] J. Folkman, "Angiogenesis-dependent diseases," Seminars in Oncology, vol. 28, no. 6, pp. 536-542, 2001.

[20] W. W. Li, M. Hutnik, and V. W. Li, "Angiogenesis-based medicine: principles and practice for disease prevention and intervention," in Angiogenesis: Basic Science and Clinical Applications, M. E. Maragoudakis and E. Papadimitriou, Eds., pp. 377-417, 2007.

[21] Angiogenesis Foundation, 2011.

[22] 2011, http://www.clinicaltrials.gov/.

[23] F. Tosetti, N. Ferrari, S. de Flora, and A. Albini, "Angioprevention: angiogenesis is a common and key target for cancer chemopreventive agents," The Federation of American Societies for Experimental Biology Journal, vol. 16, no. 1, pp. $2-14,2002$.

[24] A. Albini, D. M. Noonan, and N. Ferrari, "Molecular pathways for cancer angioprevention," Clinical Cancer Research, vol. 13, no. 15, part 1, pp. 4320-4325, 2007.

[25] G. Helmlinger, F. Yuan, M. Dellian, and R. K. Jain, "Interstitial $\mathrm{pH}$ and $\mathrm{pO} 2$ gradients in solid tumors in vivo: highresolution measurements reveal a lack of correlation," Nature Medicine, vol. 3, no. 2, pp. 177-182, 1997.

[26] C. E. Gargett and P. A. W. Rogers, "Human endometrial angiogenesis," Reproduction, vol. 121, no. 2, pp. 181-186, 2001.

[27] T. M. Hazzard and R. L. Stouffer, "Angiogenesis in ovarian follicular and luteal development," Baillière's Clinical Obstetrics and Gynaecology, vol. 14, no. 6, pp. 883-900, 2000.

[28] L. P. Reynolds and D. A. Redmer, "Angiogenesis in the placenta," Biology of Reproduction, vol. 64, no. 4, pp. 10331040, 2001.

[29] M. G. Tonnesen, X. Feng, and R. A. F. Clark, "Angiogenesis in wound healing," Journal of Investigative Dermatology Symposium Proceedings, vol. 5, no. 1, pp. 40-46, 2000.

[30] W. W. Li, K. E. Talcott, A. W. Zhai, E. A. Kruger, and V. W. $\mathrm{Li}$, "The role of therapeutic angiogenesis in tissue repair and regeneration," Advances in Skin \& Wound Care., vol. 18, no. 9, pp. 491-500, 2006.

[31] Y. Shing, J. Folkman, R. Sullivan, C. Butterfield, J. Murray, and M. Klagsbrun, "Heparin affinity: purification of a tumor-derived capillary endothelial cell growth factor," Science, vol. 223, no. 4642, pp. 1296-1298, 1984.

[32] D. R. Senger, S. J. Galli, A. M. Dvorak, C. A. Perruzzi, V. Susan Harvey, and H. F. Dvorak, "Tumor cells secrete a vascular permeability factor that promotes accumulation of ascites fluid," Science, vol. 219, no. 4587, pp. 983-985, 1983.

[33] D. W. Leung, G. Cachianes, W. J. Kuang, D. V. Goeddel, and N. Ferrara, "Vascular endothelial growth factor is a secreted angiogenic mitogen," Science, vol. 246, no. 4935, pp. 13061309, 1989.

[34] J. E. Nör, J. Christensen, D. J. Mooney, and P. J. Polverini, "Vascular endothelial growth factor (VEGF)mediated angiogenesis is associated with enhanced endothelial cell survival and induction of Bcl-2 expression," American Journal of Pathology, vol. 154, no. 2, pp. 375-384, 1999.

[35] W. Risau, "Mechanisms of angiogenesis," Nature, vol. 386, no. 6626, pp. 671-674, 1997.

[36] A. Adini, T. Kornaga, F. Firoozbakht, and L. E. Benjamin, "Placental growth factor is a survival factor for tumor endothelial cells and macrophages," Cancer Research, vol. 62, no. 10, pp. 2749-2752, 2002. 
[37] K. Hattori, B. Heissig, Y. Wu et al., "Placental growth factor reconstitutes hematopoiesis by recruiting VEGFR1+ stem cells from bone-marrow microenvironment," Nature Medicine, vol. 8, no. 8, pp. 841-849, 2002.

[38] J. Folkman and M. Klagsbrun, “Angiogenic factors," Science, vol. 235, no. 4787, pp. 442-447, 1987.

[39] R. Thommen, R. Humar, G. Misevic et al., "PDGF-BB increases endothelial migration and cord movements during angiogenesis in vitro," Journal of Cellular Biochemistry, vol. 64, no. 3, pp. 403-413, 1997.

[40] K. S. Russell, D. F. Stern, P. J. Polverini, and J. R. Bender, "Neuregulin activation of ErbB receptors in vascular endothelium leads to angiogenesis," American Journal of Physiology-Heart and Circulatory Physiology, vol. 277, no. 6, pp. H2205-H2211, 1999.

[41] P. Gillis, U. Savla, O. V. Volpert et al., "Keratinocyte growth factor induces angiogenesis and protects endothelial barrier function," Journal of Cell Science, vol. 112, no. 12, pp. 20492057, 1999.

[42] V. W. Li, R. D. Folkerth, H. Watanabe et al., "Basic fibroblast growth factor in the cerebrospinal fluid of children with brain tumours-correlation with microvessel count in the tumour," The Lancet, vol. 344, pp. 82-86, 1994.

[43] M. Nguyen, "Angiogenic factors as tumor markers," Investigational New Drugs, vol. 15, no. 1, pp. 29-37, 1997.

[44] H. Brem and J. Folkman, "Inhibition of tumor angiogenesis mediated by cartilage," Journal of Experimental Medicine, vol. 141, no. 2, pp. 427-439, 1975.

[45] M. A. Moses, D. Wiederschain, I. Wu et al., "Troponin I is present in human cartilage and inhibits angiogenesis," Proceedings of the National Academy of Sciences of the United States of America, vol. 96, no. 6, pp. 2645-2650, 1999.

[46] L. Feldman and C. Rouleau, "Troponin I inhibits capillary endothelial cell proliferation by interaction with the cell's bFGF receptor," Microvascular Research, vol. 63, no. 1, pp. 4149, 2002.

[47] I. Inoki, T. Shiomi, G. Hashimoto et al., "Connective tissue growth factor binds vascular endothelial growth factor (VEGF) and inhibits VEGF-induced angiogenesis," The Federation of American Societies for Experimental Biology Journal, vol. 16, no. 2, pp. 219-221, 2002.

[48] K. Kusafuka, Y. Hiraki, C. Shukunami, T. Kayano, and T. Takemura, "Cartilage-specific matrix protein, chondromodulin-I (ChM-I), is a strong angio-inhibitor in endochondral ossification of human neonatal vertebral tissues in vivo: relationship with angiogenic factors in the cartilage," Acta Histochemica, vol. 104, no. 2, pp. 167-175, 2002.

[49] C. D. L. Davies, R. J. Melder, L. L. Munn, C. MoutaCarreira, R. K. Jain, and Y. Boucher, "Decorin inhibits endothelial migration and tube-like structure formation: role of thrombospondin-1," Microvascular Research, vol. 62, no. 1, pp. 26-42, 2001.

[50] N. Liu, R. K. Lapcevich, C. B. Underhill et al., "Metastatin: a hyaluronan-binding complex from cartilage that inhibits tumor growth," Cancer Research, vol. 61, no. 3, pp. 10221028, 2001.

[51] D. W. Dawson, O. V. Volpert, P. Gillis et al., "Pigment epithelium-derived factor: a potent inhibitor of angiogenesis," Science, vol. 285, no. 5425, pp. 245-248, 1999.

[52] G. A. Lutty, D. C. Thompson, and J. Y. Gallup, "Vitreous: an inhibitor of retinal extract-induced neovascularization," Investigative Ophthalmology and Visual Science, vol. 24, no. 1, pp. 52-56, 1983.
[53] G. A. Williams, R. Eisenstein, B. Schumacher, K. C. Hsiao, and D. Grant, "Inhibitor of vascular endothelial cell growth in the lens," American Journal of Ophthalmology, vol. 97, no. 3, pp. 366-371, 1984.

[54] E. C. Mun, S. R. Doctrow, R. Carter et al., "An angiogenesis inhibitor from the cornea," Investigative Ophthalmology \& Visual Science, vol. 30, p. 151, 1989.

[55] W. Auerbach and R. Auerbach, "Angiogenesis inhibition: a review," Pharmacology and Therapeutics, vol. 63, no. 3, pp. 265-311, 1994.

[56] K. M. Dameron, O. V. Volpert, M. A. Tainsky, and N. Bouck, "Control of angiogenesis in fibroblasts by p53 regulation of thrombospondin-1," Science, vol. 265, no. 5178, pp. 15821584, 1994.

[57] J. E. Nör, R. S. Mitra, M. M. Sutorik, D. J. Mooney, V. P. Castle, and P. J. Polverini, "Thrombospondin-1 induces endothelial cell apoptosis and inhibits angiogenesis by activating the caspase death pathway," Journal of Vascular Research, vol. 37, no. 3, pp. 209-218, 2000.

[58] M. Streit, L. Riccardi, P. Velasco et al., "Thrombospondin2: a potent endogenous inhibitor of tumor growth and angiogenesis," Proceedings of the National Academy of Sciences of the United States of America, vol. 96, no. 26, pp. 1488814893, 1999.

[59] R. K. Singh, M. Gutman, C. D. Bucana, R. Sanchez, N. Llansa, and I. J. Fidler, "Interferons $\alpha$ and $\beta$ down-regulate the expression of basic fibroblast growth factor in human carcinomas," Proceedings of the National Academy of Sciences of the United States of America, vol. 92, no. 10, pp. 4562-4566, 1995.

[60] R. Friesel, A. Komoriya, and T. Maciag, "Inhibition of endothelial cell proliferation by gamma-interferon," Journal of Cell Biology, vol. 104, no. 3, pp. 689-696, 1987.

[61] G. D. Kamphaus, P. C. Colorado, D. J. Panka et al., "Canstatin, a novel matrix-derived inhibitor of angiogenesis and tumor growth," Journal of Biological Chemistry, vol. 275, no. 2, pp. 1209-1215, 2000.

[62] Y. Maeshima, M. Manfredi, C. Reimerli et al., "Identification of the anti-angiogenic site within vascular basement membrane-derived tumstatin," Journal of Biological Chemistry, vol. 276, no. 18, pp. 15240-15248, 2001.

[63] P. C. Colorado, A. Torre, G. Kamphaus et al., "Antiangiogenic cues from vascular basement membrane collagen," Cancer Research, vol. 60, no. 9, pp. 2520-2526, 2000.

[64] M. S. O’Reilly, L. Holmgren, Y. Shing et al., "Angiostatin: a novel angiogenesis inhibitor that mediates the suppression of metastases by a Lewis lung carcinoma," Cell, vol. 79, no. 2, pp. 315-328, 1994.

[65] H. H. Heidtmann, D. M. Nettelbeck, A. Mingels, R. Jäger, H. G. Welker, and R. E. Kontermann, "Generation of angiostatin-like fragments from plasminogen by prostatespecific antigen," British Journal of Cancer, vol. 81, no. 8, pp. 1269-1272, 1999.

[66] S. Gately, P. Twardowski, M. S. Stack et al., "The mechanism of cancer-mediated conversion of plasminogen to the angiogenesis inhibitor angiostatin," Proceedings of the National Academy of Sciences of the United States of America, vol. 94, no. 20, pp. 10868-10872, 1997.

[67] M. S. O’Reilly, T. Boehm, Y. Shing et al., "Endostatin: an endogenous inhibitor of angiogenesis and tumor growth," Cell, vol. 88, no. 2, pp. 277-285, 1997.

[68] J. Dixelius, H. Larsson, T. Sasaki et al., "Endostatin-induced tyrosine kinase signaling through the Shb adaptor protein 
regulates endothelial cell apoptosis," Blood, vol. 95, no. 11, pp. 3403-3411, 2000.

[69] M. S. O’Reilly, L. Holmgren, Y. Shing et al., "Angiostatin: a circulating endothelial cell inhibitor that suppresses angiogenesis and tumor growth," Cold Spring Harbor Symposia on Quantitative Biology, vol. 59, pp. 471-482, 1994.

[70] R. S. Herbst, K. R. Hess, H. T. Tran et al., "Phase I study of recombinant human endostatin in patients with advanced solid tumors," Journal of Clinical Oncology, vol. 20, no. 18, pp. 3792-3803, 2002.

[71] D. Hanahan and J. Folkman, "Patterns and emerging mechanisms of the angiogenic switch during tumorigenesis," Cell, vol. 86, no. 3, pp. 353-364, 1996.

[72] K. H. Plate, G. Breier, B. Millauer, A. Ullrich, and W. Risau, "Up-regulation of vascular endothelial growth factor and its cognate receptors in a rat glioma model of tumor angiogenesis," Cancer Research, vol. 53, no. 23, pp. 58225827, 1993.

[73] F. Rastinejad, P. J. Polverini, and N. P. Bouck, "Regulation of the activity of a new inhibitor of angiogenesis by a cancer suppressor gene," Cell, vol. 56, no. 3, pp. 345-355, 1989.

[74] K. Ohno-Matsui, I. Morita, J. Tombran-Tink et al., "Novel mechanism for age-related macular degeneration: an equilibrium shift between the angiogenesis factors VEGF and PEDF," Journal of Cellular Physiology, vol. 189, no. 3, pp. 323333, 2001.

[75] D. Lyden, A. Z. Young, D. Zagzag et al., "Id1 and Id3 are required for neurogenesis, angiogenesis and vascularization of tumour xenografts," Nature, vol. 401, no. 6754, pp. 670 $677,1999$.

[76] T. A. Baudino, C. McKay, H. Pendeville-Samain et al., "C-Myc is essential for vasculogenesis and angiogenesis during development and tumor progression," Genes and Development, vol. 16, no. 19, pp. 2530-2543, 2002.

[77] F. Vikhanskaya, M. R. Bani, P. Borsotti et al., "P73 overexpression increases VEGF and reduces thrombospondin-1 production: implications for tumor angiogenesis," Oncogene, vol. 20, no. 50, pp. 7293-7300, 2001.

[78] L. Lu, K. Holmqvist, M. Cross, and M. Welsh, "Role of the Src homology 2 domain-containing protein Shb in murine brain endothelial cell proliferation and differentiation," Cell Growth and Differentiation, vol. 13, no. 3, pp. 141-148, 2002.

[79] J. Rak, Y. Mitsuhashi, L. Bayko et al., "Mutant ras oncogenes upregulate VEGF/VPF expression: implications for induction and inhibition of tumor angiogenesis," Cancer Research, vol. 55, no. 20, pp. 4575-4580, 1995.

[80] S. Grugel, G. Finkenzeller, K. Weindel, B. Barleon, and D. Marme, "Both v-Ha-Ras and v-Raf stimulate expression of the vascular endothelial growth factor in NIH 3T3 cells," Journal of Biological Chemistry, vol. 270, no. 43, pp. 2591525919, 1995.

[81] J. L. Arbiser, M. A. Moses, C. A. Fernandez et al., "Oncogenic H-ras stimulates tumor angiogenesis by two distinct pathways," Proceedings of the National Academy of Sciences of the United States of America, vol. 94, no. 3, pp. 861-866, 1997.

[82] J. Schlessinger, "New roles for Src kinases in control of cell survival and angiogenesis," Cell, vol. 100, no. 3, pp. 293-296, 2000.

[83] R. Kumar and R. Yarmand-Bagheri, "The role of HER2 in angiogenesis," Seminars in Oncology, vol. 28, no. 5, supplement 16, pp. 27-32, 2001.

[84] D. Giri and M. Ittmann, "Inactivation of the PTEN tumor suppressor gene is associated with increased angiogenesis in clinically localized prostate carcinoma," Human Pathology, vol. 30, no. 4, pp. 419-424, 1999.

[85] P. P. Claudio, P. Stiegler, C. M. Howard et al., "RB2/p130 gene-enhanced expression down-regulates vascular endothelial growth factor expression and inhibits angiogenesis in vivo," Cancer Research, vol. 61, no. 2, pp. 462-468, 2001.

[86] C. Blancher, J. W. Moore, N. Robertson, and A. L. Harris, "Effects of ras and von Hippel-Lindau (VHL) gene mutations on hypoxia-inducible factor (HIF)- $1 \alpha$, HIF- $2 \alpha$, and vascular endothelial growth factor expression and their regulation by the phosphatidylinositol 3'-kinase/Akt signaling pathway," Cancer Research, vol. 61, no. 19, pp. 7349-7355, 2001.

[87] C. Y. Li, S. Shan, Q. Huang et al., "Initial stages of tumor cellinduced angiogenesis: evaluation via skin window chambers in rodent models," Journal of the National Cancer Institute, vol. 92, no. 2, pp. 143-147, 2000.

[88] J. Holash, P. C. Maisonpierre, D. Compton et al., "Vessel cooption, regression, and growth in tumors mediated by angiopoietins and VEGF," Science, vol. 284, no. 5422, pp. 1994-1998, 1999.

[89] J. Folkman, "Incipient angiogenesis," Journal of the National Cancer Institute, vol. 92, no. 2, pp. 94-95, 2000.

[90] L. Holmgren, M. S. O’Reilly, and J. Folkman, "Dormancy of micrometastases: balanced proliferation and apoptosis in the presence of angiogenesis suppression," Nature Medicine, vol. 1, no. 2, pp. 149-153, 1995.

[91] W. W. Li, "Tumor angiogenesis: molecular pathology, therapeutic targeting, and imaging," Academic Radiology, vol. 7, no. 10, pp. 800-811, 2000.

[92] D. Hanahan, "Heritable formation of pancreatic $\beta$-cell tumours in transgenic mice expressing recombinant insulin/simian virus 40 oncogenes," Nature, vol. 315, no. 6015, pp. 115-122, 1985.

[93] J. Folkman and D. Hanahan, "Expression of the angiogenic phenotype during development of murine and human cancer," in Origins of Human Cancer: A Comprehensive Review, J. Brugge, T. Curran, E. Harlow et al., Eds., pp. 803-814, Cold Spring Harbor Laboratory Press, Cold Spring Harbor, NY, USA, 1991.

[94] J. Folkman, K. Watson, D. Ingber, and D. Hanahan, "Induction of angiogenesis during the transition from hyperplasia to neoplasia," Nature, vol. 339, no. 6219, pp. 58-61, 1989.

[95] M. Lacey, S. Alpert, and D. Hanahan, "Bovine papillomavirus genome elicits skin tumours in transgenic mice," Nature, vol. 322, no. 6080, pp. 609-612, 1986.

[96] J. Kandel, E. Bossy-Wetzel, F. Radvanyi, M. Klagsbrun, J. Folkman, and D. Hanahan, "Neovascularization is associated with a switch to the export of bFGF in the multistep development of fibrosarcoma," Cell, vol. 66, no. 6, pp. 10951104, 1991.

[97] G. Bergers, D. Hanahan, and L. M. Coussens, "Angiogenesis and apoptosis are cellular parameters of neoplastic progression in transgenic mouse models of tumorigenesis," International Journal of Developmental Biology, vol. 42, no. 7, pp. 995-1002, 1998.

[98] L. M. Coussens, W. W. Raymond, G. Bergers et al., "Inflammatory mast cells up-regulate angiogenesis during squamous epithelial carcinogenesis," Genes and Development, vol. 13, no. 11, pp. 1382-1397, 1999.

[99] K. Norrby, "Mast cells and angiogenesis: review article," Acta Pathologica, Microbiologica et Immunologica Scandinavica, vol. 110, no. 5, pp. 355-371, 2002.

[100] D. Ribatti, E. Crivellato, L. Candussio et al., "Mast cells and their secretory granules are angiogenic in the chick 
embryo chorioallantoic membrane," Clinical and Experimental Allergy, vol. 31, no. 4, pp. 602-608, 2001.

[101] K. Smith-McCune, Y. H. Zhu, D. Hanahan, and J. Arbeit, "Cross-species comparison of angiogenesis during the premalignant stages of squamous carcinogenesis in the human cervix and K14-HPV16 transgenic mice," Cancer Research, vol. 57, no. 7, pp. 1294-1300, 1997.

[102] J. Folkman, "Tumor angiogenesis," in Cancer Biology, F. F. Becker, Ed., vol. 3 of Biology of Tumors, pp. 355-388, Plenum Press, New York, NY, USA, 1975.

[103] F. Wurschmidt, H. P. Beck-Bornholdt, and H. Vogler, "Radiobiology of the rhabdomyosarcoma $\mathrm{R} 1 \mathrm{H}$ of the rat: influence of the size of irradiation field on tumor response, tumor bed effect, and neovascularization kinetics," International Journal of Radiation Oncology Biology Physics, vol. 18, no. 4, pp. 879882, 1990.

[104] H. Yamaura, K. Yamada, and T. Matsuzawa, "Radiation effect on the proliferating capillaries in rat transparent chambers," International Journal of Radiation Biology, vol. 30, no. 2, pp. 179-187, 1976.

[105] M. A. Gimbrone Jr., S. B. Leapman, R. S. Cotran, and J. Folkman, "Tumor dormancy in vivo by prevention of neovascularization,” Journal of Experimental Medicine, vol. 136, no. 2, pp. 261-276, 1972.

[106] J. Folkman, "Tumor angiogenesis and tissue factor," Nature Medicine, vol. 2, no. 2, pp. 167-168, 1996.

[107] R. A. Modzelewski, P. Davies, S. C. Watkins, R. Auerbach, M. J. Chang, and C. S. Johnson, "Isolation and identification of fresh tumor-derived endothelial cells from a murine RIF-1 fibrosarcoma," Cancer Research, vol. 54, no. 2, pp. 336-339, 1994.

[108] W. D. Thompson, K. J. Shiach, and R. A. Fraser, "Tumours acquire their vasculature by vessel incorporation, not vessel ingrowth," Journal of Pathology, vol. 151, no. 4, pp. 323-332, 1987.

[109] I. J. Fidler and L. M. Ellis, "The implications of angiogenesis for the biology and therapy of cancer metastasis," Cell, vol. 79, no. 2, pp. 185-188, 1994.

[110] T. P. Butler and P. M. Gullino, "Quantitation of cell shedding into efferent blood of mammary adenocarcinoma," Cancer Research, vol. 35, no. 3, pp. 512-516, 1975.

[111] J. Folkman, "Antiangiogenesis agents," in Cancer Principles \& Practice of Oncology, V. T. DeVita, S. Hellman, and S. A. Rosenberg, Eds., pp. 509-519, Lippincott Williams \& Wilkins, Philadelphia, Pa, USA, 6th edition, 2001.

[112] R. L. Engerman, D. Pfaffenbach, and M. D. Davis, "Cell turnover of capillaries," Laboratory Investigation, vol. 17, no. 6, pp. 738-743, 1967.

[113] B. Hobson and J. Denekamp, "Endothelial proliferation in tumours and normal tissues: continuous labelling studies," British Journal of Cancer, vol. 49, no. 4, pp. 405-413, 1984.

[114] I. F. Tannock, "Population kinetics of carcinoma cells, capillary endothelial cells, and fibroblasts in a transplanted mouse mammary tumor," Cancer Research, vol. 30, no. 10, pp. 2470-2476, 1970.

[115] D. H. Ausprunk and J. Folkman, "Migration and proliferation of endothelial cells in preformed and newly formed blood vessels during tumor angiogenesis," Microvascular Research, vol. 14, no. 1, pp. 53-65, 1977.

[116] C. W. White, H. M. Sondheimer, E. C. Crouch, H. Wilson, and L. L. Fan, "Treatment of pulmonary hemangiomatosis with recombinant interferon alfa-2a," The New England Journal of Medicine, vol. 320, no. 18, pp. 1197-1200, 1989.
[117] E. A. Kruger and W. D. Figg, "TNP-470: an angiogenesis inhibitor in clinical development for cancer," Expert Opinion on Investigational Drugs, vol. 9, no. 6, pp. 1383-1396, 2000.

[118] J. M. Pluda, "Tumor-associated angiogenesis: mechanisms, clinical implications, and therapeutic strategies," Seminars in Oncology, vol. 24, no. 2, pp. 203-218, 1997.

[119] J. Folkman, P. Hahnfeldt, and L. Hlatky, "The logic of antiangiogenic gene therapy," in The Development of Human Gene Therapy, T. Friedman, Ed., pp. 527-543, Cold Spring Harbor Laboratory Press, Cold Spring Harbor, NY, USA, 1998.

[120] R. S. Herbst, A. T. Lee, H. T. Tran, and J. L. Abbruzzese, "Clinical studies of angiogenesis inhibitors: the University of Texas MD Anderson Center Trial of Human Endostatin," Current Oncology Reports, vol. 3, no. 2, pp. 131-140, 2001.

[121] S. A. Hill, G. M. Tozer, G. R. Pettit, and D. J. Chaplin, "Preclinical evaluation of the antitumour activity of the novel vascular targeting agent Oxi 4503," Anticancer Research, vol. 22, no. 3, pp. 1453-1458, 2002.

[122] H. Goto, S. Yano, H. Zhang et al., "Activity of a new vascular targeting agent, ZD6126, in pulmonary metastases by human lung adenocarcinoma in nude mice," Cancer Research, vol. 62, no. 13, pp. 3711-3715, 2002.

[123] D. W. Siemann, E. Mercer, S. Lepler, and A. M. Rojiani, "Vascular targeting agents enhance chemotherapeutic agent activities in solid tumor therapy," International Journal of Cancer, vol. 99, no. 1, pp. 1-6, 2002.

[124] H. Brem and J. Folkman, "Analysis of experimental antiangiogenic therapy," Journal of Pediatric Surgery, vol. 28, no. 3, pp. 445-451, 1993.

[125] W. W. Li, V. W. Li, R. Casey et al., "Clinical trials of angiogenesis based therapies: overview and new guiding principles," in Angiogenesis Models, Modulators and Clinical Application, M. Maragoudakis, Ed., pp. 475-492, Plenum Press, New York, NY, USA, 1998.

[126] N. B. Teo, B. S. Shoker, L. Martin, J. P. Sloane, and C. Holcombe, "Angiogenesis in pre-invasive cancers," Anticancer Research, vol. 22, no. 4, pp. 2061-2072, 2002.

[127] P. Vajkoczy, M. Farhadi, A. Gaumann et al., "Microtumor growth initiates angiogenic sprouting with simultaneous expression of VEGF, VEGF receptor-2, and angiopoietin-2," Journal of Clinical Investigation, vol. 109, no. 6, pp. 777-785, 2002.

[128] A. H. S. Lee, L. C. Happerfield, L. G. Borrow, and R. R. Millis, "Angiogenesis and inflammation in ductal carcinoma in situ of the breast," Journal of Pathology, vol. 181, no. 2, pp. 200206, 1997.

[129] A. Fisseler-Eckhoff, D. Rothstein, and K. M. Müller, "Neavascularization in hyperplastic, metaplastic and potentially preneoplastic lesions of the bronchial mucosa," Virchows Archiv, vol. 429, no. 2-3, pp. 95-100, 1996.

[130] M. P. Wong, N. Cheung, S. T. Yuen, S. Y. Leung, and L. P. Chung, "Vascular endothelial growth factor is upregulated in the early pre-malignant stage of colorectal tumour progression," International Journal of Cancer, vol. 81, no. 6, pp. 845-850, 1999.

[131] A. Dellas, H. Moch, and E. Schultheiss, "Angiogenesis in cervical neoplasia microvessel quantification in precancerous lesions and invasive carcinomas with clinicopathological correlations," Gynecologic Oncology, vol. 67, no. 1, pp. 27-33, 1997.

[132] K. K. Smith-McCune and N. Weidner, "Demonstration and characterization of the angiogenic properties of cervical dysplasia," Cancer Research, vol. 54, no. 3, pp. 800-804, 1994. 
[133] G. W. Chodak, C. Haudenschild, R. F. Gittes, and J. Folkman, "Angiogenic activity as a marker of neoplastic and preneoplastic lesions of the human bladder," Annals of Surgery, vol. 192, no. 6, pp. 762-771, 1980.

[134] J. C. Watson, E. Sutanto-Ward, M. Osaku, J. K. Weinstein, J. S. Babb, and E. R. Sigurdson, "Importance of timing and length of administration of angiogenesis inhibitor TNP-470 in the treatment of $\mathrm{K} 12 / \mathrm{TRb}$ colorectal hepatic metastases in BD-IX rats," Surgery, vol. 126, no. 2, pp. 358-363, 1999.

[135] Y. Fong, L. H. Blumgart, and A. M. Cohen, "Surgical treatment of colorectal metastases to the liver," $\mathrm{Ca}$-A Cancer Journal for Clinicians, vol. 45, no. 1, pp. 50-62, 1995.

[136] S. Paku and K. Lapis, "Morphological aspects of angiogenesis in experimental liver metastases," American Journal of Pathology, vol. 143, no. 3, pp. 926-936, 1993.

[137] D. Ingber, T. Fujita, S. Kishimoto et al., "Synthetic analogs of fumagillin that inhibit angiogenesis and suppress tumour growth," Nature, vol. 348, pp. 555-557, 1990.

[138] Y. Suganuma, T. Takahashi, H. Taniguchi, K. Takeuchi, Y. Ueshima, and H. Tanaka, "Inhibitory effect of antiangiogenic agent TNP-470 (AGM-14710) on liver metastasis of VX2 carcinoma in rabbits," Regional Cancer Treatment, vol. 7, no. 3-4, pp. 160-162, 1994.

[139] S. Shusterman, S. A. Grupp, R. Barr, D. Carpentieri, H. Zhao, and J. M. Maris, "The angiogenesis inhibitor TNP-470 effectively inhibits human neuroblastoma xenograft growth, especially in the setting of subclinical disease," Clinical Cancer Research, vol. 7, no. 4, pp. 977-984, 2001.

[140] G. Bergers, K. Javaherian, K. M. Lo, J. Folkman, and D. Hanahan, "Effects of angiogenesis inhibitors on multistage carcinogenesis in mice," Science, vol. 284, no. 5415, pp. 808812, 1999.

[141] I. B. J. K. Joseph, J. Vukanovic, and J. T. Isaacs, "Antiangiogenic treatment with linomide as chemoprevention for prostate, seminal vesicle, and breast carcinogenesis in rodents," Cancer Research, vol. 56, no. 15, pp. 3404-3408, 1996.

[142] W. Bollag, "Experimental basis of cancer combination chemotherapy with retinoids, cytokines, 1,25-dihydroxyvitamin D3, and analogs," Journal of Cellular Biochemistry, vol. 56, no. 4, pp. 427-435, 1994.

[143] D. J. Mantell, P. E. Owens, N. J. Bundred, E. B. Mawer, and A. E. Canfield, " $1 \alpha, 25$-dihydroxyvitamin D3 inhibits angiogenesis in vitro and in vivo," Circulation Research, vol. 87, no. 3, pp. 214-220, 2000.

[144] L. P. Marson, K. M. Kurian, W. R. Miller, and J. M. Dixon, "The effect of tamoxifen on breast tumour vascularity," Breast Cancer Research and Treatment, vol. 66, no. 1, pp. 9-15, 2001.

[145] B. A. Ruggeri, C. Robinson, T. Angeles, J. Wilkinson, and M. L. Clapper, "The chemopreventive agent oltipraz possesses potent antiangiogenic activity in vitro, ex vivo, and in vivo and inhibits tumor xenograft growth," Clinical Cancer Research, vol. 8, no. 1, pp. 267-274, 2002.

[146] M. W. Lingen, P. J. Polverini, and N. P. Bouck, "Inhibition of squamous cell carcinoma angiogenesis by direct interaction of retinoic acid with endothelial cells," Laboratory Investigation, vol. 74, no. 2, pp. 476-483, 1996.

[147] Y. Takahashi, M. Mai, and K. Nishioka, "Alphadifluoromethylornithine induces apoptosis as well as antiangiogenesis in the inhibition of tumor growth and metastasis in a human gastric cancer model," International Journal of Cancer, vol. 85, no. 2, pp. 243-247, 2000.

[148] C. Jiang, W. Jiang, C. Ip, H. Ganther, and J. Lu, "Seleniuminduced inhibition of angiogenesis in mammarycancer at chemopreventive levels of intake," Molecular Carcinogenesis, vol. 26, no. 4, pp. 213-225, 1999.

[149] T. Cai, G. Fassina, M. Morini et al., "N-acetylcysteine inhibits endothelial cell invasion and angiogenesis," Laboratory Investigation, vol. 79, no. 9, pp. 1151-1159, 1999.

[150] S. E. Ebeler, C. A. Brenneman, G. S. Kim et al., "Dietary catechin delays tumor onset in a transgenic mouse model," American Journal of Clinical Nutrition, vol. 76, no. 4, pp. 865872, 2002.

[151] Z. Wang, C. F. Fuentes, and S. M. Shapshay, "Antiangiogenic and chemopreventive activities of celecoxib in oral carcinoma cell," Laryngoscope, vol. 112, no. 5, pp. 839-842, 2002.

[152] S. Sharma, M. Ghoddoussi, P. Gao, G. J. Kelloff, V. E. Steele, and L. Kopelovich, "A quantitative angiogenesis model for efficacy testing of chemopreventive agents," Anticancer Research, vol. 21, no. 6, pp. 3829-3837, 2001.

[153] E. A. Kruger, P. H. Duray, D. K. Price, J. M. Pluda, and W. D. Figg, "Approaches to preclinical screening of antiangiogenic agents," Seminars in Oncology, vol. 28, no. 6, pp. 570-576, 2001.

[154] G. Perletti, P. Concari, R. Giardini et al., "Antitumor activity of endostatin against carcinogen-induced rat primary mammary tumors," Cancer Research, vol. 60, no. 7, pp. 1793-1796, 2000.

[155] C. S. Yang and Z. Y. Wang, "Tea and cancer," Journal of the National Cancer Institute, vol. 85, no. 13, pp. 1038-1049, 1993.

[156] Z. Y. Wang, L. D. Wang, M. J. Lee et al., "Inhibition of $N$ nitrosomethylbenzylamine-induced esophageal tumorigenesis in rats by green and black tea," Carcinogenesis, vol. 16, no. 9, pp. 2143-2148, 1995.

[157] G. Y. Yang, Z. Y. Wang, S. Kim et al., "Characterization of early pulmonary hyperproliferation and tumor progression and their inhibition by black tea in a 4-(methylnitrosamino)-1- (3-pyridyl)-1-butanone-induced lung tumorigenesis model with A/J mice," Cancer Research, vol. 57, no. 10, pp. 1889-1894, 1997.

[158] Z. Y. Wang, S. J. Cheng, Z. C. Zhou et al., "Antimutagenic activity of green tea polyphenols," Mutation Research, vol. 223, no. 3, pp. 273-285, 1989.

[159] Z. Y. Wang, J. Y. Hong, M. T. Huang, K. R. Reuhl, A. H. Conney, and C. S. Yang, "Inhibition of $N$-nitrosodiethylamine- and 4-(methylnitrosamino)-1-(3- pyridyl)1-butanone-induced tumorigenesis in A/J mice by green tea and black tea," Cancer Research, vol. 52, no. 7, pp. 1943-1947, 1992.

[160] M. Sazuka, S. Murakami, M. Isemura, K. Satoh, and T. Nukiwa, "Inhibitory effects of green tea infusion on in vitro invasion and in vivo metastasis of mouse lung carcinoma cells," Cancer Letters, vol. 98, no. 1, pp. 27-31, 1995.

[161] S. Taniguchi, H. Fujiki, H. Kobayashi et al., "Effect of (-)epigallocatechin gallate, the main constituent of green tea, on lung metastasis with mouse B16 melanoma cell lines," Cancer Letters, vol. 65, no. 1, pp. 51-54, 1992.

[162] J. Liao, G. Y. Yang, E. S. Park et al., "Inhibition of lung carcinogenesis and effects on angiogenesis and apoptosis in A/J mice by oral administration of green tea," Nutrition and Cancer, vol. 48, no. 1, pp. 44-53, 2004.

[163] Y. Cao and R. Cao, "Angiogenesis inhibited by drinking tea," Nature, vol. 398, no. 6726, p. 381, 1999.

[164] S. Garbisa, S. Biggin, N. Cavallarin, L. Sartor, R. Benelli, and A. Albini, "Tumor invasion: molecular shears blunted by green tea," Nature Medicine, vol. 5, no. 11, p. 1216, 1999. 
[165] S. Garbisa, L. Sartor, S. Biggin, B. Salvato, R. Benelli, and A. Albini, "Tumor gelatinases and invasion inhibited by the green tea flavanol epigallocatechin-3-gallate," Cancer, vol. 91, no. 4, pp. 822-832, 2001.

[166] Y. P. Lu, Y. R. Lou, J. G. Xie et al., "Topical applications of caffeine or (-)-epigallocatechin gallate (EGCG) inhibit carcinogenesis and selectively increase apoptosis in UVBinduced skin tumors in mice," Proceedings of the National Academy of Sciences of the United States of America, vol. 99, no. 19, pp. 12455-12460, 2002.

[167] S. Bettuzzi, M. Brausi, F. Rizzi, G. Castagnetti, G. Peracchia, and A. Corti, "Chemoprevention of human prostate cancer by oral administration of green tea catechins in volunteers with high-grade prostate intraepithelial neoplasia: a preliminary report from a one-year proof-of-principle study," Cancer Research, vol. 66, no. 2, pp. 1234-1240, 2006.

[168] M. Shimizu, Y. Fukutomi, M. Ninomiya et al., "Green tea extracts for the prevention of metachronous colorectal adenomas: a pilot study," Cancer Epidemiology Biomarkers and Prevention, vol. 17, no. 11, pp. 3020-3025, 2008.

[169] N. Li, Z. Sun, C. Han, and J. Chen, "The chemopreventive effects of tea on human oral precancerous mucosa lesions," Proceedings of the Society for Experimental Biology and Medicine, vol. 220, no. 4, pp. 218-224, 1999.

[170] W. S. Ahn, J. Yoo, S. W. Huh et al., "Protective effects of green tea extracts (polyphenon E and EGCG) on human cervical lesions," European Journal of Cancer Prevention, vol. 12, no. 5, pp. 383-390, 2003.

[171] V. W. Li and W. W. Li, "Antiangiogenesis in the treatment of skin cancer," Journal of Drugs in Dermatology, vol. 6, no. 11, pp. S17-S24, 2007.

[172] C. A. Lamartiniere, M. S. Cotroneo, W. A. Fritz, J. Wang, R. Mentor-Marcel, and A. Elgavish, "Genistein chemoprevention: timing and mechanisms of action in murine mammary and prostate," Journal of Nutrition, vol. 132, no. 3, pp. 552S558S, 2002.

[173] M. S. Cotroneo, J. Wang, W. A. Fritz, I. E. Eltoum, and C. A. Lamartiniere, "Genistein action in the prepubertal mammary gland in a chemoprevention model," Carcinogenesis, vol. 23, no. 9, pp. 1467-1474, 2002.

[174] A. I. Constantinou, D. Lantvit, M. Hawthorne, X. Xu, R. B. van Breemen, and J. M. Pezzuto, "Chemopreventive effects of soy protein and purified soy isoflavones on DMBA-induced mammary tumors in female Sprague-Dawley rats," Nutrition and Cancer, vol. 41, no. 1-2, pp. 75-81, 2001.

[175] A. Brown, P. Jolly, and H. Wei, "Genistein modulates neuroblastoma cell proliferation and differentiation through induction of apoptosis and regulation of tyrosine kinase activity and N-myc expression," Carcinogenesis, vol. 19, no. 6, pp. 991-997, 1998.

[176] J. N. Davis, O. Kucuk, and F. H. Sarkar, "Genistein inhibits NF- $\kappa \mathrm{B}$ activation in prostate cancer cells," Nutrition and Cancer, vol. 35, no. 2, pp. 167-174, 1999.

[177] R. A. Dixon and D. Ferreira, "Genistein," Phytochemistry, vol. 60, no. 3, pp. 205-211, 2002.

[178] T. Fotsis, M. Pepper, H. Adlercreutz et al., "Genistein, a dietary-derived inhibitor of in vitro angiogenesis," Proceedings of the National Academy of Sciences of the United States of America, vol. 90, no. 7, pp. 2690-2694, 1993.

[179] T. Akiyama, J. Ishida, S. Nakagawa et al., "Genistein, a specific inhibitor of tyrosine-specific protein kinases," Journal of Biological Chemistry, vol. 262, no. 12, pp. 5592-5595, 1987.

[180] H. Adlercreutz, H. Honjo, A. Higashi et al., "Urinary excretion of lignans and isoflavonoid phytoestrogens in
Japanese men and women consuming a traditional Japanese diet," American Journal of Clinical Nutrition, vol. 54, no. 6, pp. 1093-1100, 1991.

[181] T. Fotsis, M. Pepper, H. Adlercreutz, T. Hase, R. Montesano, and L. Schweigerer, "Genistein, a dietary ingested isoflavonoid, inhibits cell proliferation and in vitro angiogenesis," Journal of Nutrition, vol. 125, no. 3, pp. 790S-797S, 1995.

[182] S. A. Lee, X. O. Shu, H. Li et al., "Adolescent and adult soy food intake and breast cancer risk: results from the Shanghai women's health study," American Journal of Clinical Nutrition, vol. 89, no. 6, pp. 1920-1926, 2009.

[183] C. Muir, J Waterhouse, T. Mack et al., Cancer Incidence in Five Continents, vol. 5, International Agency for Research on Cancer, Lyon, France, 1987.

[184] L. A. Korde, A. H. Wu, T. Fears et al., "Childhood soy intake and breast cancer risk in Asian American women," Cancer Epidemiology Biomarkers and Prevention, vol. 18, no. 4, pp. 1050-1059, 2009.

[185] R. K. Severson, A. M. Y. Nomura, J. S. Grove, and G. N. Stemmermann, "A prospective study of demographics, diet, and prostate cancer among men of Japanese ancestry in Hawaii," Cancer Research, vol. 49, no. 7, pp. 1857-1860, 1989.

[186] Angiogenesis Foundation Clinical Trials Database, 2011.

[187] X. O. Shu, Y. Zheng, H. Cai et al., "Soy food intake and breast cancer survival," Journal of the American Medical Association, vol. 302, no. 22, pp. 2437-2443, 2009.

[188] M. Jang, L. Cai, G. O. Udeani et al., "Cancer chemopreventive activity of resveratrol, a natural product derived from grapes," Science, vol. 275, no. 5297, pp. 218-220, 1997.

[189] Y. Kimura and H. Okuda, "Resveratrol isolated from polygonum cuspidatum root prevents tumor growth and metastasis to lung and tumor-induced neovascularization in Lewis lung carcinoma-bearing mice," Journal of Nutrition, vol. 131, no. 6, pp. 1844-1849, 2001.

[190] E. Bråkenhielm, R. Cao, and Y. Cao, "Suppression of angiogenesis, tumor growth, and wound healing by resveratrol, a natural compound in red wine and grapes," The Federation of American Societies for Experimental Biology Journal, vol. 15, no. 10, pp. 1798-1800, 2001.

[191] A. A. E. Bertelli, R. Baccalini, E. Battaglia, M. Falchi, and M. E. Ferrero, "Resveratrol inhibits TNF $\alpha$-induced endothelial cell activation,” Therapie, vol. 56, no. 5, pp. 613-616, 2001.

[192] K. Igura, T. Ohta, Y. Kuroda, and K. Kaji, "Resveratrol and quercetin inhibit angiogenesis in vitro," Cancer Letters, vol. 171, no. 1, pp. 11-16, 2001.

[193] S. Banerjee, C. Bueso-Ramos, and B. B. Aggarwal, "Suppression of 7,12-dimethylbenz(a)anthracene-induced mammary carcinogenesis in rats by resveratrol: role of nuclear factor$\kappa \mathrm{B}$, cyclooxygenase 2, and matrix metalloprotease 9," Cancer Research, vol. 62, no. 17, pp. 4945-4954, 2002.

[194] C. Chao, J. M. Slezak, B. J. Caan, and V. P. Quinn, “Alcoholic beverage intake and risk of lung cancer: the California men's health study," Cancer Epidemiology Biomarkers and Prevention, vol. 17, no. 10, pp. 2692-2699, 2008.

[195] A. Ruano-Ravina, A. Figueiras, and J. M. Barros-Dios, “Type of wine and risk of lung cancer: a case-control study in Spain," Thorax, vol. 59, no. 11, pp. 981-985, 2004.

[196] S. Sutcliffe, E. Giovannucci, M. F. Leitzmann et al., "A prospective cohort study of red wine consumption and risk of prostate cancer," International Journal of Cancer, vol. 120, no. 7, pp. 1529-1535, 2007. 
[197] W. B. Wu, H. S. Chiang, J. Y. Fang, and C. F. Hung, "Inhibitory effect of lycopene on POGF-BB-induced signalling and migration in human dermal fibroblasts: a possible target for cancer," Biochemical Society Transactions, vol. 35, part 5, pp. 1377-1378, 2007.

[198] C. S. Huang, J. W. Liao, and M. L. Hu, "Lycopene inhibits experimental metastasis of human hepatoma SK-Hep-1 cells in athymic nude mice," Journal of Nutrition, vol. 138, no. 3, pp. 538-543, 2008.

[199] E. Giovannucci, E. B. Rimm, Y. Liu, M. J. Stampfer, and W. C. Willett, "A prospective study of tomato products, lycopene, and prostate cancer risk," Journal of the National Cancer Institute, vol. 94, no. 5, pp. 391-398, 2002.

[200] E. M. Grainger, S. J. Schwartz, S. Wang et al., "A combination of tomato and soy products for men with recurring prostate cancer and rising prostate specific antigen," Nutrition and Cancer, vol. 60, no. 2, pp. 145-154, 2008.

[201] L. Chen, M. Stacewicz-Sapuntzakis, C. Duncan et al., "Oxidative DNA damage in prostate cancer patients consuming tomato sauce-based entrees as a whole-food intervention," Journal of the National Cancer Institute, vol. 93, no. 24, pp. 1872-1879, 2001.

[202] M. Szymczak, M. Murray, and N. Petrovic, "Modulation of angiogenesis by $\omega-3$ polyunsaturated fatty acids is mediated by cyclooxygenases," Blood, vol. 111, no. 7, pp. 3514-3521, 2008.

[203] W. Friedrichs, S. B. Ruparel, R. A. Marciniak et al., "Omega3 fatty acid inhibition of prostate cancer progression to hormone independence is associated with suppression of mTOR signaling and androgen receptor expression," Nutrition and Cancer, vol. 10, pp. 1-7, 2011.

[204] C. C. Mandal, T. Ghosh-Choudhury, T. Yoneda, G. G. Choudhury, and N. Ghosh-Choudhury, "Fish oil prevents breast cancer cell metastasis to bone," Biochemical and Biophysical Research Communications, vol. 402, no. 4, pp. 602-607, 2010.

[205] Z. Gong, E. A. Holly, F. Wang, J. M. Chan, and P. M. Bracci, "Intake of fatty acids and antioxidants and pancreatic cancer in a large population-based case-control study in the San Francisco Bay area," International Journal of Cancer, vol. 127, no. 8, pp. 1893-1904, 2010.

[206] K. M. Szymanski, D. C. Wheeler, and L. A. Mucci, "Fish consumption and prostate cancer risk: a review and metaanalysis," The American Journal of Clinical Nutrition, vol. 92, no. 5, pp. 1223-1233, 2010.

[207] H. Yao, H. Wang, Z. Zhang, B. H. Jiang, J. Luo, and X. Shi, "Sulforaphane inhibited expression of hypoxia-inducible factor- $1 \alpha$ in human tongue squamous cancer cells and prostate cancer cells," International Journal of Cancer, vol. 123, no. 6, pp. 1255-1261, 2008.

[208] R. Davis, K. P. Singh, R. Kurzrock, and S. Shankar, "Sulforaphane inhibits angiogenesis through activation of FOXO transcription factors," Oncology Reports, vol. 22, no. 6, pp. 1473-1478, 2009.

[209] M. Asakage, N. H. Tsuno, J. Kitayama et al., "Sulforaphane induces inhibition of human umbilical vein endothelial cells proliferation by apoptosis," Angiogenesis, vol. 9, no. 2, pp. 8391, 2006.

[210] H. T. Wu, S. H. Lin, and Y. H. Chen, "Inhibition of cell proliferation and in vitro markers of angiogenesis by indole3 -carbinol, a major indole metabolite present in cruciferous vegetables," Journal of Agricultural and Food Chemistry, vol. 53, no. 13, pp. 5164-5169, 2005.
[211] K. Kunimasa, T. Kobayashi, S. Sugiyama, K. Kaji, and T. Ohta, "Indole-3-carbinol suppresses tumor-induced angiogenesis by inhibiting tube formation and inducing apoptosis," Bioscience, Biotechnology and Biochemistry, vol. 72, no. 8, pp. 2243-2246, 2008.

[212] F. L. Büchner, H. B. Bueno-de-Mesquita, J. Linseisen et al., "Fruits and vegetables consumption and the risk of histological subtypes of lung cancer in the European prospective investigation into cancer and nutrition (EPIC)," Cancer Causes and Control, vol. 21, no. 3, pp. 357-371, 2010.

[213] H. Boeing, T. Dietrich, K. Hoffmann et al., "Intake of fruits and vegetables and risk of cancer of the upper aerodigestive tract: the prospective EPIC-study," Cancer Causes and Control, vol. 17, no. 7, pp. 957-969, 2006.

[214] C. A. Thompson, T. M. Habermann, A. H. Wang et al., "Antioxidant intake from fruits, vegetables and other sources and risk of non-Hodgkin's lymphoma: the Iowa women's health study," International Journal of Cancer, vol. 126, no. 4, pp. 992-1003, 2010.

[215] M. A. Gates, S. S. Tworoger, J. L. Hecht, I. de Vivo, B. Rosner, and S. E. Hankinson, "A prospective study of dietary flavonoid intake and incidence of epithelial ovarian cancer," International Journal of Cancer, vol. 121, no. 10, pp. 22252232, 2007.

[216] E. Ansó, A. Zuazo, M. Irigoyen, M. C. Urdaci, A. Rouzaut, and J. J. Martínez-Irujo, "Flavonoids inhibit hypoxia-induced vascular endothelial growth factor expression by a HIF-1 independent mechanism," Biochemical Pharmacology, vol. 79, no. 11, pp. 1600-1609, 2010.

[217] M. Pilátová, V. Stupáková, L. Varinská et al., "Effect of selected flavones on cancer and endothelial cells," General Physiology and Biophysics, vol. 29, no. 2, pp. 134-143, 2010.

[218] S. J. Oh, O. Kim, J. S. Lee et al., "Inhibition of angiogenesis by quercetin in tamoxifen-resistant breast cancer cells," Food and Chemical Toxicology, vol. 48, no. 11, pp. 3227-3234, 2010.

[219] C. D. Davis, N. J. Emenaker, and J. A. Milner, "Cellular proliferation, apoptosis and angiogenesis: molecular targets for nutritional preemption of cancer," Seminars in Oncology, vol. 37, no. 3, pp. 243-257, 2010.

[220] J. D. Kim, L. Liu, W. Guo et al., "Chemical structure of flavanols in relation to modulation of angiogenesis and immune-endothelial cell adhesion," Journal of Nutritional Biochemistry, vol. 17, no. 3, pp. 165-176, 2006.

[221] http://www.nal.usda.gov/fnic/foodcomp/Data/Other/EB03_ VegFlav.pdf.

[222] D. Heimler, L. Isolani, P. Vignolini, S. Tombelli, and A. Romani, "Polyphenol content and antioxidative activity in some species of freshly consumed salads," Journal of Agricultural and Food Chemistry, vol. 55, no. 5, pp. 17241729, 2007.

[223] K. A. Steinmetz, J. D. Potter, and A. R. Folsom, "Vegetables, fruit, and lung cancer in the Iowa women's health study," Cancer Research, vol. 53, no. 3, pp. 536-543, 1993.

[224] C. Galeone, C. Pelucchi, F. Levi et al., "Onion and garlic use and human cancer," American Journal of Clinical Nutrition, vol. 84, no. 5, pp. 1027-1032, 2006.

[225] E. Dorant, P. A. V. D. Brandt, R. A. Goldbohm, and F. Sturmans, "Consumption of onions and a reduced risk of stomach carcinoma," Gastroenterology, vol. 110, no. 1, pp. 12-20, 1996.

[226] M. Schulz, P. H. Lahmann, H. Boeing et al., "Fruit and vegetable consumption and risk of epithelial ovarian cancer: 
the European Prospective Investigation into Cancer and Nutrition," Cancer Epidemiology Biomarkers and Prevention, vol. 14, no. 11, part 1, pp. 2531-2535, 2005.

[227] L. S. Wang, S. S. Hecht, S. G. Carmella et al., "Anthocyanins in black raspberries prevent esophageal tumors in rats," Cancer Prevention Research, vol. 2, no. 1, pp. 84-93, 2009.

[228] G. D. Stoner, T. Chen, L. A. Kresty, R. M. Aziz, T. Reinemann, and R. Nines, "Protection against esophageal cancer in rodents with lyophilized berries: potential mechanisms," Nutrition and Cancer, vol. 54, no. 1, pp. 33-46, 2006.

[229] L. S. Wang, A. A. Dombkowski, C. Seguin et al., "Mechanistic basis for the chemopreventive effects of black raspberries at a late stage of rat esophageal carcinogenesis," Molecular Carcinogenesis, vol. 50, no. 4, pp. 291-300, 2011.

[230] H. Lu, J. Li, D. Zhang, G. D. Stoner, and C. Huang, "Molecular mechanisms involved in chemoprevention of black raspberry extracts: from transcription factors to their target genes," Nutrition and Cancer, vol. 54, no. 1, pp. 69-78, 2006.

[231] B. S. Shumway, L. A. Kresty, P. E. Larsen et al., "Effects of a topically applied bioadhesive berry gel on loss of heterozygosity indices in premalignant oral lesions," Clinical Cancer Research, vol. 14, no. 8, pp. 2421-2430, 2008.

[232] L. Gu, M. A. Kelm, J. F. Hammerstone et al., "Concentrations of proanthocyanidins in common foods and estimations of normal consumption," Journal of Nutrition, vol. 134, no. 3, pp. 613-617, 2004.

[233] R. A. Dixon, D. Y. Xie, and S. B. Sharma, "Proanthocyanidins-a final frontier in flavonoid research?" New Phytologist, vol. 165, no. 1, pp. 9-28, 2005.

[234] D. Y. Xie and R. A. Dixon, "Proanthocyanidin biosynthesisstill more questions than answers?" Phytochemistry, vol. 66, no. 18, pp. 2127-2144, 2005.

[235] L. Gu, S. E. House, X. Wu, B. Ou, and R. L. Prior, "Procyanidin and catechin contents and antioxidant capacity of cocoa and chocolate products," Journal of Agricultural and Food Chemistry, vol. 54, no. 11, pp. 4057-4061, 2006.

[236] N. Camu, T. de Winter, S. K. Addo, J. S. Takrama, H. Bernaert, and L. de Vuyst, "Fermentation of cocoa beans: influence of microbial activities and polyphenol concentrations on the flavour of chocolate," Journal of the Science of Food and Agriculture, vol. 88, no. 13, pp. 2288-2297, 2008.

[237] T. P. Kenny, C. L. Keen, P. Jones, H. J. Kung, H. H. Schmitz, and M. E. Gershwin, "Cocoa procyanidins inhibit proliferation and angiogenic signals in human dermal microvascular endothelial cells following stimulation by low-level $\mathrm{H}_{2} \mathrm{O}_{2}$," Experimental Biology and Medicine, vol. 229, no. 8, pp. 765$771,2004$.

[238] J. E. Kim, J. E. Son, S. K. Jung et al., "Cocoa polyphenols suppress TNF- $\alpha$-induced vascular endothelial growth factor expression by inhibiting phosphoinositide 3-kinase (PI3K) and mitogen-activated protein kinase kinase-1 (MEK1) activities in mouse epidermal cells," British Journal of Nutrition, vol. 104, no. 7, pp. 957-964, 2010.

[239] L. Y. Rios, R. N. Bennett, S. A. Lazarus, C. Rémésy, A. Scalbert, and G. Williamson, "Cocoa procyanidins are stable during gastric transit in humans," American Journal of Clinical Nutrition, vol. 76, no. 5, pp. 1106-1110, 2002.

[240] I. A. L. Persson, K. Persson, S. Hägg, and R. G. G. Andersson, "Effects of cocoa extract and dark chocolate on angiotensinconverting enzyme and nitric oxide in human endothelial cells and healthy volunteers-a nutrigenomics perspective," Journal of Cardiovascular Pharmacology, vol. 57, no. 1, pp. 44-50, 2011.
[241] R. di Giuseppe, A. Di Castelnuovo, F. Centritto et al., "Regular consumption of dark chocolate is associated with low serum concentrations of C-reactive protein in a healthy italian population," Journal of Nutrition, vol. 138, no. 10, pp. 1939-1945, 2008.

[242] N. K. Hollenberg, N. D. L. Fisher, and M. L. McCullough, "Flavanols, the Kuna, cocoa consumption, and nitric oxide," Journal of the American Society of Hypertension, vol. 3, no. 2, pp. 105-112, 2009.

[243] H. Schroeter, C. Heiss, J. Balzer et al., “(-)-Epicatechin mediates beneficial effects of flavanol-rich cocoa on vascular function in humans," Proceedings of the National Academy of Sciences of the United States of America, vol. 103, no. 4, pp. 1024-1029, 2006.

[244] J. Lu, K. Zhang, S. Nam, R. A. Anderson, R. Jove, and W. Wen, "Novel angiogenesis inhibitory activity in cinnamon extract blocks VEGFR2 kinase and downstream signaling," Carcinogenesis, vol. 31, no. 3, pp. 481-488, 2010.

[245] H. K. Kwon, W. K. Jeon, J. S. Hwang et al., "Cinnamon extract suppresses tumor progression by modulating angiogenesis and the effector function of CD8+ T cells," Cancer Letters, vol. 278, no. 2, pp. 174-182, 2009.

[246] X. Wu, L. Gu, R. L. Prior, and S. McKay, "Characterization of anthocyanins and proanthocyanidins in some cultivars of Ribes, Aronia, and Sambucus and their antioxidant capacity," Journal of Agricultural and Food Chemistry, vol. 52, no. 26, pp. 7846-7856, 2004.

[247] S. Roy, S. Khanna, H. M. Alessio et al., "Anti-angiogenic property of edible berries," Free Radical Research, vol. 36, no. 9, pp. 1023-1031, 2002.

[248] A. Bishayee, T. Mbimba, R. J. Thoppil et al., "Anthocyaninrich black currant (Ribes nigrum L.) extract affords chemoprevention against diethylnitrosamine-induced hepatocellular carcinogenesis in rats," Journal of Nutritional Biochemistry. In press.

[249] E. Pappas and K. M. Schaich, "Phytochemicals of cranberries and cranberry products: characterization, potential health effects, and processing stability," Critical Reviews in Food Science and Nutrition, vol. 49, no. 9, pp. 741-781, 2009.

[250] B. A. Déziel, K. Pate, C. Neto, K. Gottschall-Pass, and R. A. R. Hurta, "Proanthocyanidins from the American Cranberry (Vaccinium macrocarpon) inhibit matrix metalloproteinase2 and matrix metalloproteinase-9 activity in human prostate cancer cells via alterations in multiple cellular signalling pathways," Journal of Cellular Biochemistry, vol. 111, no. 3, pp. 742-754, 2010.

[251] J. Boateng, M. Verghese, L. Shackelford et al., "Selected fruits reduce azoxymethane (AOM)-induced aberrant crypt foci (ACF) in Fisher 344 male rats," Food and Chemical Toxicology, vol. 45, no. 5, pp. 725-732, 2007.

[252] H. Zessner, L. Pan, F. Will et al., "Fractionation of polyphenol-enriched apple juice extracts to identify constituents with cancer chemopreventive potential," Molecular Nutrition and Food Research, vol. 52, no. 1, pp. S28-S44, 2008.

[253] D. Feskanich, R. G. Ziegler, D. S. Michaud et al., "Prospective study of fruit and vegetable consumption and risk of lung cancer among men and women," Journal of the National Cancer Institute, vol. 92, no. 22, pp. 1812-1823, 2000.

[254] P. Knekt, J. Kumpulainen, R. Järvinen et al., "Flavonoid intake and risk of chronic diseases," American Journal of Clinical Nutrition, vol. 76, no. 3, pp. 560-568, 2002.

[255] L. Le Marchand, S. P. Murphy, J. H. Hankin, L. R. Wilkens, and L. N. Kolonel, "Intake of flavonoids and lung cancer," 
Journal of the National Cancer Institute, vol. 92, no. 2, pp. 154-160, 2000.

[256] S. Gallus, R. Talamini, A. Giacosa et al., "Does an apple a day keep the oncologist away?" Annals of Oncology, vol. 16, no. 11, pp. 1841-1844, 2005.

[257] E. Bakkalbaşi, O. Menteş, and N. Artik, "Food ellagitanninsoccurrence, effects of processing and storage," Critical Reviews in Food Science and Nutrition, vol. 49, no. 3, pp. 283298, 2009.

[258] A. Gonzalez-Sarrias, J. C. Espin, F. A. Tomas-Barberan et al., "Comparative transcriptional analysis reveals key cell cycle and MAPK signaling genes involved in the S-G2M-phase arrest of Caco- 2 cells exposed to ellagic acid and its colonic derivatives, urolithins," Molecular Nutrition \& Food Research, vol. 53, pp. 686-698, 2009.

[259] R. Tzulker, I. Glazer, I. Bar-Ilan, D. Holland, M. Aviram, and R. Amir, "Antioxidant activity, polyphenol content, and related compounds in different fruit juices and homogenates prepared from 29 different pomegranate accessions," Journal of Agricultural and Food Chemistry, vol. 55, no. 23, pp. 95599570, 2007.

[260] N. P. Seeram, L. S. Adams, S. M. Henning et al., "In vitro antiproliferative, apoptotic and antioxidant activities of punicalagin, ellagic acid and a total pomegranate tannin extract are enhanced in combination with other polyphenols as found in pomegranate juice," Journal of Nutritional Biochemistry, vol. 16, no. 6, pp. 360-367, 2005.

[261] M. R. Sartippour, N. P. Seeram, J. Y. Rao et al., "Ellagitanninrich pomegranate extract inhibits angiogenesis in prostate cancer in vitro and in vivo," International Journal of Oncology, vol. 32, no. 2, pp. 475-480, 2008.

[262] A. J. Pantuck, J. T. Leppert, N. Zomorodian et al., "Phase II study of pomegranate juice for men with rising prostatespecific antigen following surgery or radiation for prostate cancer," Clinical Cancer Research, vol. 12, no. 13, pp. 40184026, 2006.

[263] H. Yoshiji, S. Kuriyama, R. Noguchi et al., "Amelioration of carcinogenesis and tumor growth in the rat liver by combination of vitamin $\mathrm{K} 2$ and angiotensin-converting enzyme inhibitor via anti-angiogenic activities," Oncology Reports, vol. 15, no. 1, pp. 155-159, 2006.

[264] K. Nimptsch, S. Rohrmann, R. Kaaks, and J. Linseisen, "Dietary vitamin K intake in relation to cancer incidence and mortality: results from the Heidelberg cohort of the European Prospective Investigation into Cancer and Nutrition (EPIC-Heidelberg)," American Journal of Clinical Nutrition, vol. 91, no. 5, pp. 1348-1358, 2010.

[265] D. Habu, S. Shiomi, A. Tamori et al., "Role of vitamin K2 in the development of hepatocellular carcinoma in women with viral cirrhosis of the liver," Journal of the American Medical Association, vol. 292, no. 3, pp. 358-361, 2004.

[266] S. Perkins, R. D. Verschoyle, K. Hill et al., "Chemopreventive efficacy and pharmacokinetics of curcumin in the $\mathrm{min} /+$ mouse, a model of familial adenomatous polyposis," Cancer Epidemiology Biomarkers and Prevention, vol. 11, no. 6, pp. 535-540, 2002.

[267] A. Goel, C. R. Boland, and D. P. Chauhan, "Specific inhibition of cyclooxygenase-2 (COX-2) expression by dietary curcumin in HT-29 human colon cancer cells," Cancer Letters, vol. 172, no. 2, pp. 111-118, 2001.

[268] T. Dorai, Y. C. Cao, B. Dorai, R. Buttyan, and A. E. Katz, "Therapeutic potential of curcumin in human prostate cancer. III. Curcumin inhibits proliferation, induces apoptosis, and inhibits angiogenesis of $\mathrm{LNCaP}$ prostate cancer cells in vivo," Prostate, vol. 47, no. 4, pp. 293-303, 2001.

[269] A. E. Gururaj, M. Belakavadi, D. A. Venkatesh, D. Marmé, and B. P. Salimath, "Molecular mechanisms of antiangiogenic effect of curcumin," Biochemical and Biophysical Research Communications, vol. 297, no. 4, pp. 934-942, 2002.

[270] Z. M. Shao, Z. Z. Shen, C. H. Liu et al., "Curcumin exerts multiple suppressive effects on human breast carcinoma cells," International Journal of Cancer, vol. 98, no. 2, pp. 234240, 2002.

[271] R. Mohan, J. Sivak, P. Ashton et al., "Curcuminoids inhibit the angiogenic response stimulated by fibroblast growth factor-2, including expression of matrix metalloproteinase gelatinase B," Journal of Biological Chemistry, vol. 275, no. 14, pp. 10405-10412, 2000.

[272] E. Y. Shin, S. Y. Kim, and E. G. Kim, "C-jun N-terminal kinase is involved in motility of endothelial cell," Experimental and Molecular Medicine, vol. 33, no. 4, pp. 276-283, 2001.

[273] D. Thaloor, A. K. Singh, G. S. Sidhu, P. V. Prasad, H. K. Kleinman, and R. K. Maheshwari, "Inhibition of angiogenic differentiation of human umbilical vein endothelial cells by curcumin," Cell Growth and Differentiation, vol. 9, no. 4, pp. 305-312, 1998.

[274] A. L. Chen, C. H. Hsu, J. K. Lin et al., "Phase I clinical trial of curcumin, a chemopreventive agent, in patients with highrisk or pre-malignant lesions," Anticancer Research, vol. 21, no. 4, pp. 2895-2900, 2001.

[275] R. E. Carroll, R. V. Benya, D. K. Turgeon et al., "Phase IIa clinical trial of curcumin for the prevention of colorectal neoplasia," Cancer Prevention Research, vol. 4, no. 3, pp. 354364, 2011.

[276] R. M. Arensman and C. J. H. Stolar, "Vitamin A effect on tumor angiogenesis," Journal of Pediatric Surgery, vol. 14, no. 6, pp. 809-813, 1979.

[277] E. D. E. Liaudet-Coopman, G. J. Berchem, and A. Wellstein, "In vivo inhibition of angiogenesis and induction of apoptosis by retinoic acid in squamous cell carcinoma," Clinical Cancer Research, vol. 3, no. 2, pp. 179-184, 1997.

[278] I. Sogno, R. Venè, N. Ferrari et al., "Angioprevention with fenretinide: targeting angiogenesis in prevention and therapeutic strategies," Critical Reviews in Oncology/Hematology, vol. 75, no. 1, pp. 2-14, 2010.

[279] C. Marquez, S. M. Bair, E. Smithberger, B. S. Cherpelis, and L. F. Glass, "Systemic retinoids for chemoprevention of nonmelanoma skin cancer in high-risk patients," Journal of Drugs in Dermatology, vol. 9, no. 7, pp. 753-758, 2010.

[280] S. Hoffmann, A. Rockenstein, A. Ramaswamy et al., "Retinoic acid inhibits angiogenesis and tumor growth of thyroid cancer cells," Molecular and Cellular Endocrinology, vol. 264, no. 1-2, pp. 74-81, 2007.

[281] M. S. Irwig, A. El-Sohemy, A. Baylin, N. Rifai, and H. Campos, "Frequent intake of tropical fruits that are rich in $\beta$-cryptoxanthin is associated with higher plasma $\beta$ cryptoxanthin concentrations in Costa Rican adolescents," Journal of Nutrition, vol. 132, no. 10, pp. 3161-3167, 2002.

[282] E. M. Siegel, J. L. Salemi, L. L. Villa, A. Ferenczy, E. L. Franco, and A. R. Giuliano, "Dietary consumption of antioxidant nutrients and risk of incident cervical intraepithelial neoplasia," Gynecologic Oncology, vol. 118, no. 3, pp. 289-294, 2010.

[283] M. Pandey and V. K. Shukla, "Diet and gallbladder cancer: a case-control study," European Journal of Cancer Prevention, vol. 11, no. 4, pp. 365-368, 2002. 
[284] J. M. Yuan, D. O. Stram, K. Arakawa, H. P. Lee, and M. C. $\mathrm{Yu}$, "Dietary cryptoxanthin and reduced risk of lung cancer: the Singapore Chinese health study," Cancer Epidemiology Biomarkers and Prevention, vol. 12, no. 9, pp. 890-898, 2003.

[285] R. M. Tamimi, G. A. Colditz, and S. E. Hankinson, "Circulating carotenoids, mammographic density, and subsequent risk of breast cancer," Cancer Research, vol. 69, no. 24, pp. 9323-9329, 2009.

[286] R. G. Mehta, J. Liu, A. Constantinou et al., "Cancer chemopreventive activity of brassinin, a phytoalexin from cabbage," Carcinogenesis, vol. 16, no. 2, pp. 399-404, 1995.

[287] A. Garg, S. Garg, L. J. D. Zaneveld, and A. K. Singla, "Chemistry and pharmacology of the citrus bioflavonoid hesperidin," Phytotherapy Research, vol. 15, no. 8, pp. 655669, 2001.

[288] F. V. So, N. Guthrie, A. F. Chambers, M. Moussa, and K. K. Carroll, "Inhibition of human breast cancer cell proliferation and delay of mammary tumorigenesis by flavonoids and citrus juices," Nutrition and Cancer, vol. 26, no. 2, pp. 167181, 1996.

[289] K. Akagi, M. Hirose, T. Hoshiya, Y. Mizoguchi, N. Ito, and T. Shirai, "Modulating effects of ellagic acid, vanillin and quercetin in a rat medium term multi-organ carcinogenesis model," Cancer Letters, vol. 94, no. 1, pp. 113-121, 1995.

[290] H. Kohno, T. Tanaka, K. Kawabata et al., "Silymarin, a naturally occurring polyphenolic antioxidant flavonoid, inhibits azoxymethane-induced colon carcinogenesis in male F344 rats," International Journal of Cancer, vol. 101, no. 5, pp. 461-468, 2002.

[291] K. B. Kwon, S. J. Yoo, D. G. Ryu et al., "Induction of apoptosis by diallyl disulfide through activation of caspase-3 in human leukemia HL-60 cells," Biochemical Pharmacology, vol. 63, no. 1, pp. 41-47, 2002.

[292] J. Ferlay, H. R. Shin, F. Bray, D. Forman, C. Mathers, and D. M. Parkin, "Estimates of worldwide burden of cancer in 2008: GLOBOCAN 2008," International Journal of Cancer, vol. 127, no. 12, pp. 2893-2917, 2010.

[293] P. Boyle and B. E. Levin, Eds., World Cancer Report 2008, WHO Press, Geneva, Switzerland, 2008, http://www.iarc.fr/ en/publications/pdfs-online/wcr/2008/wcr_2008.pdf.

[294] M. L. McCullough and E. L. Giovannucci, "Diet and cancer prevention,” Oncogene, vol. 23, no. 38, pp. 6349-6364, 2004.

[295] S. R. Doll, "The lessons of life: keynote address to the nutrition and cancer conference," Cancer Research, vol. 52, no. 7, pp. 2024S-2029S, 1992.

[296] E. M. Grainger, S. J. Schwartz, S. Wang et al., "A combination of tomato and soy products for men with recurring prostate cancer and rising prostate specific antigen," Nutrition and Cancer, vol. 60, no. 2, pp. 145-154, 2008.

[297] United States Department of Agriculture, "USDA's MyPlate," http://www.choosemyplate.gov/. 


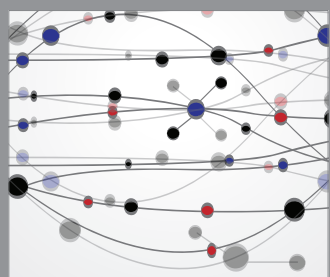

The Scientific World Journal
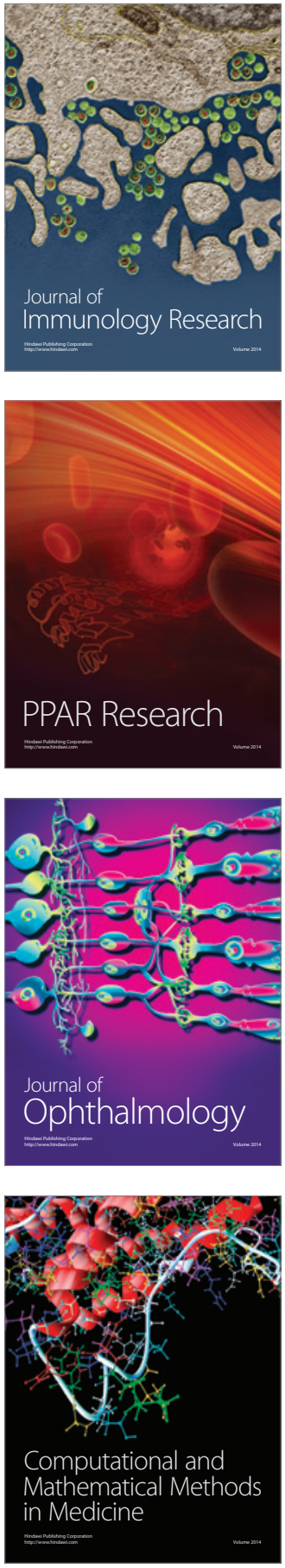

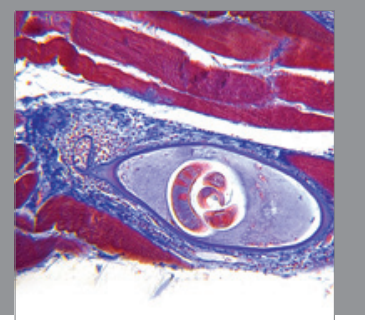

Gastroenterology

Research and Practice
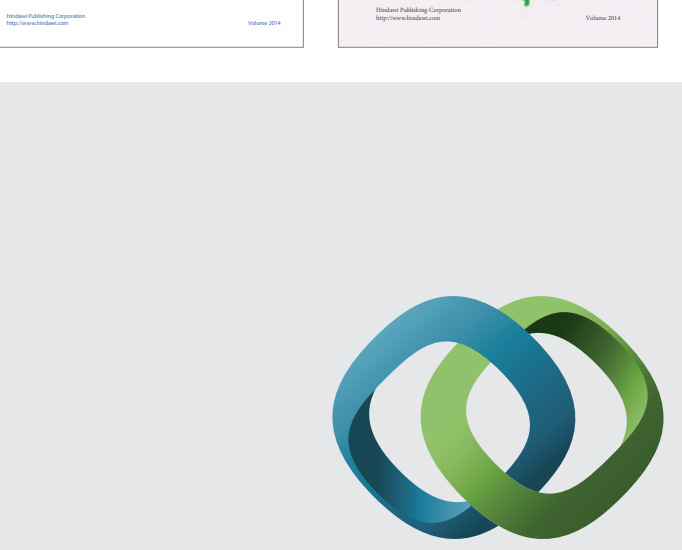

\section{Hindawi}

Submit your manuscripts at

http://www.hindawi.com
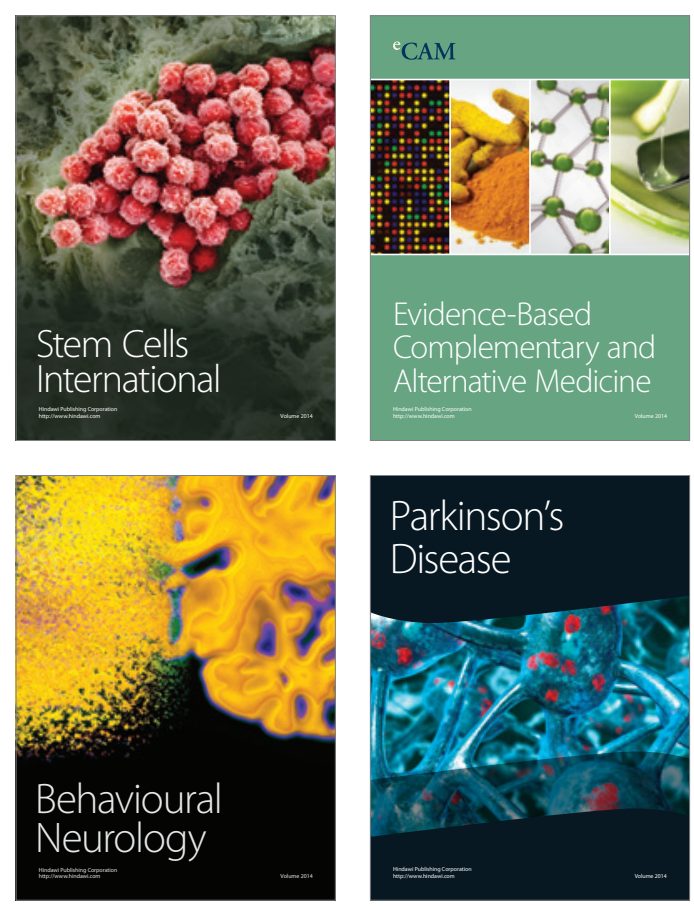

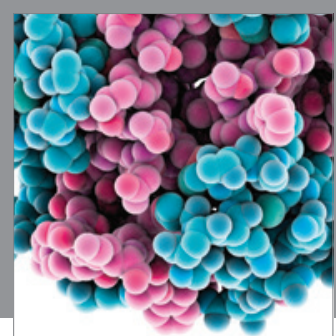

Journal of
Diabetes Research

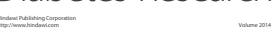

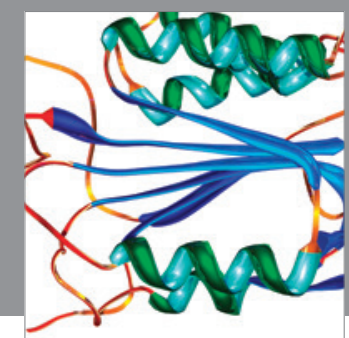

Disease Markers
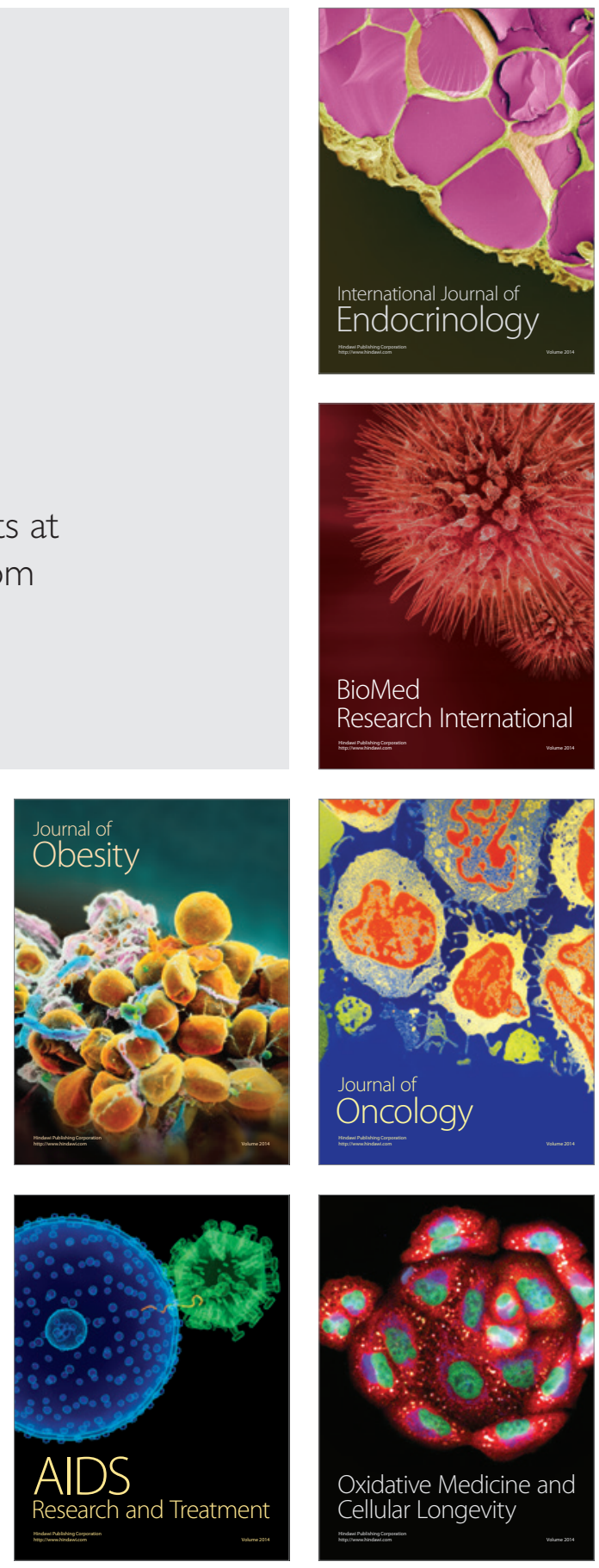